\title{
Exploring the Application of the Negishi Reaction of HaloBODIPYs: Generality, Regioselectivity and Synthetic Utility in the Development of BODIPY Laser Dyes
}

\author{
Eduardo Palao, ${ }^{\dagger}$ Gonzalo Duran-Sampedro, ${ }^{\dagger}$ Santiago de la Moya, ${ }^{*}, \dagger$ Miriam Madrid,${ }^{\dagger}$ \\ Carmen García-López, ${ }^{\dagger}$ Antonia R. Agarrabeitia,${ }^{\dagger}$ Bram Verbelen,,${ }^{\ddagger}$ Wim Dehaen,${ }^{\ddagger}$ \\ Nöel Boens ${ }^{\dagger}$ and María J. Ortiz ${ }^{*} \dagger$ \\ †Department of Organic Chemistry I, Universidad Complutense de Madrid, Facultad de Ciencias \\ Químicas, Ciudad Universitaria s/n, E-28040 Madrid, Spain \\ †Department of Chemistry, KU Leuven, Celestijnenlaan 200 f, B-3001 Leuven, Belgium
}

Table of Contents

1. ${ }^{1} \mathrm{H}$ NMR and ${ }^{13} \mathrm{C}$ NMR Spectra $\quad$ S2

2. 1D NOESY Spectra $\quad \mathbf{S 3 2}$

$\begin{array}{lr}\text { 3. 2D HMBC Spectra } & \text { S37 }\end{array}$

$\begin{array}{lr}\text { 4. References } & \mathbf{S 4 2}\end{array}$ 


\section{1. ${ }^{1} \mathrm{H}$ NMR and ${ }^{13} \mathrm{C}$ NMR Spectra}

${ }^{1} \mathrm{H}\left(300 \mathrm{MHz}, \mathrm{CDCl}_{3}\right)$ and ${ }^{13} \mathrm{C}\left(75 \mathrm{MHz}, \mathrm{CDCl}_{3}\right)$ NMR spectra of 3d
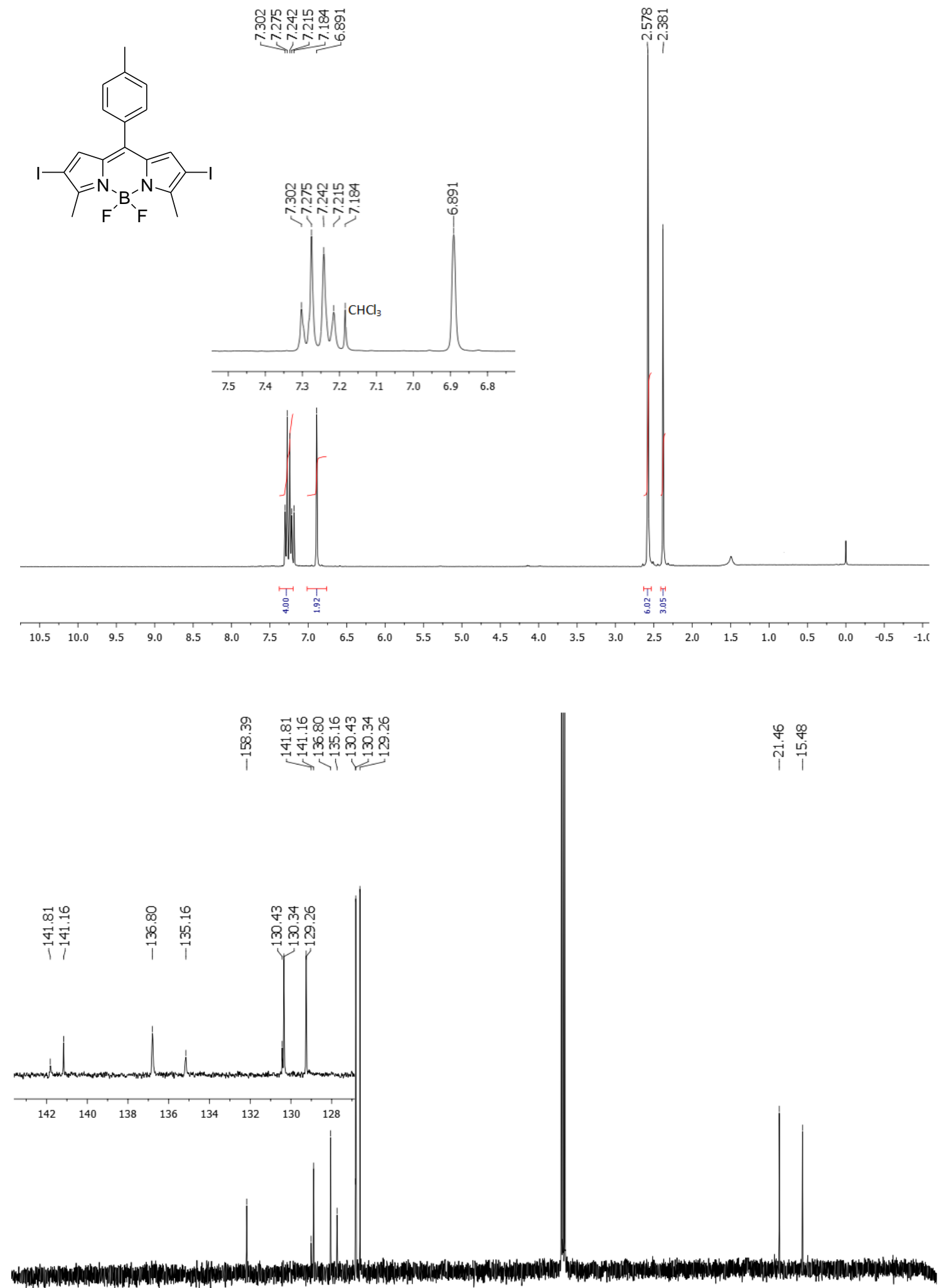

$\begin{array}{lllllllllllllllllllllllllllll}210 & 200 & 190 & 180 & 170 & 160 & 150 & 140 & 130 & 120 & 110 & 100 & 90 & 80 & 70 & 60 & 50 & 40 & 30 & 20 & 10 & 0 & -10\end{array}$ 
${ }^{1} \mathrm{H}\left(700 \mathrm{MHz}, \mathrm{CDCl}_{3}\right)$ and ${ }^{13} \mathrm{C}\left(176 \mathrm{MHz}, \mathrm{CDCl}_{3}\right)$ NMR spectra of $\mathbf{3 e}$
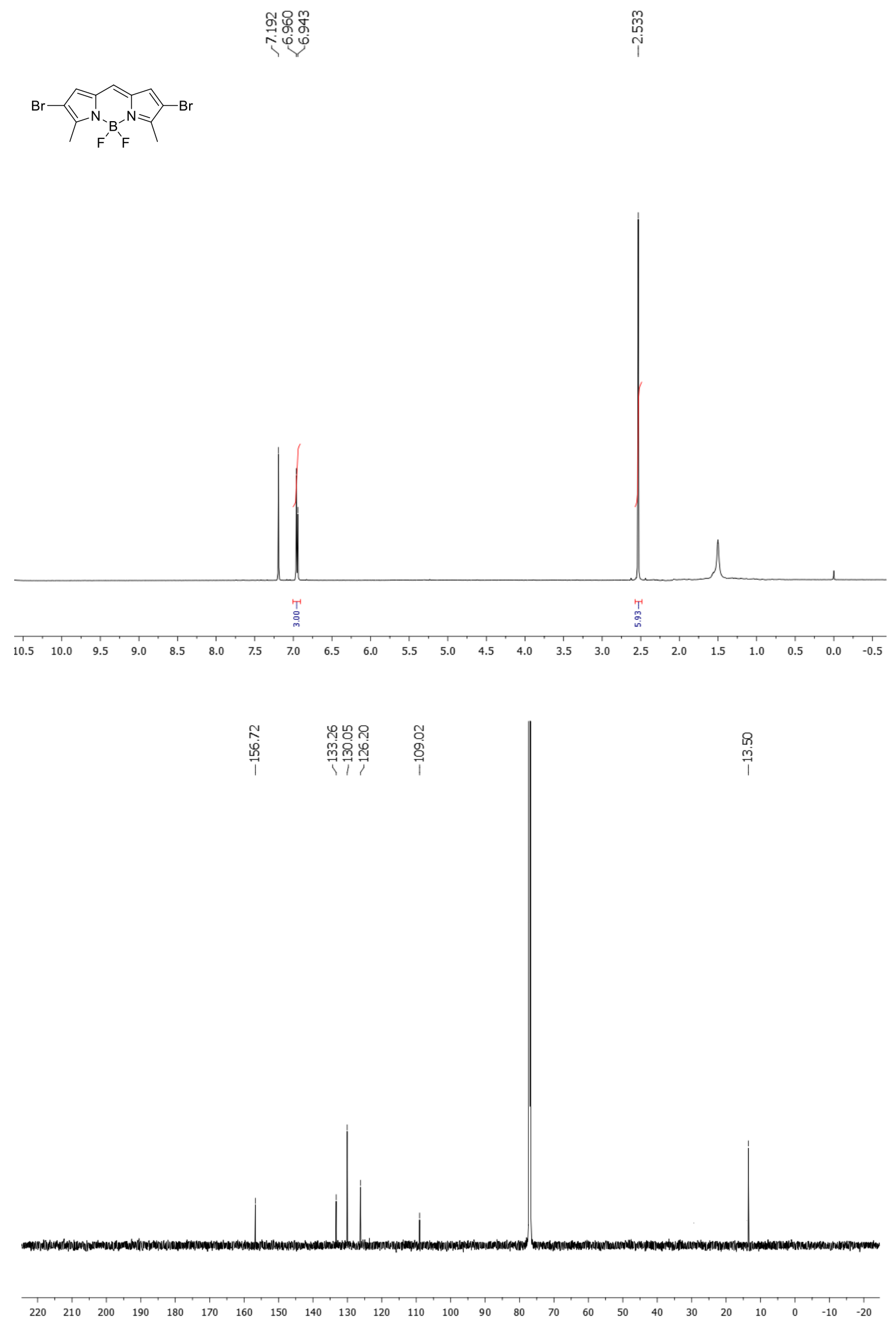
${ }^{1} \mathrm{H}\left(700 \mathrm{MHz}, \mathrm{CDCl}_{3}\right)$ and ${ }^{13} \mathrm{C}\left(176 \mathrm{MHz}, \mathrm{CDCl}_{3}\right)$ NMR spectra of $\mathbf{1 4}$
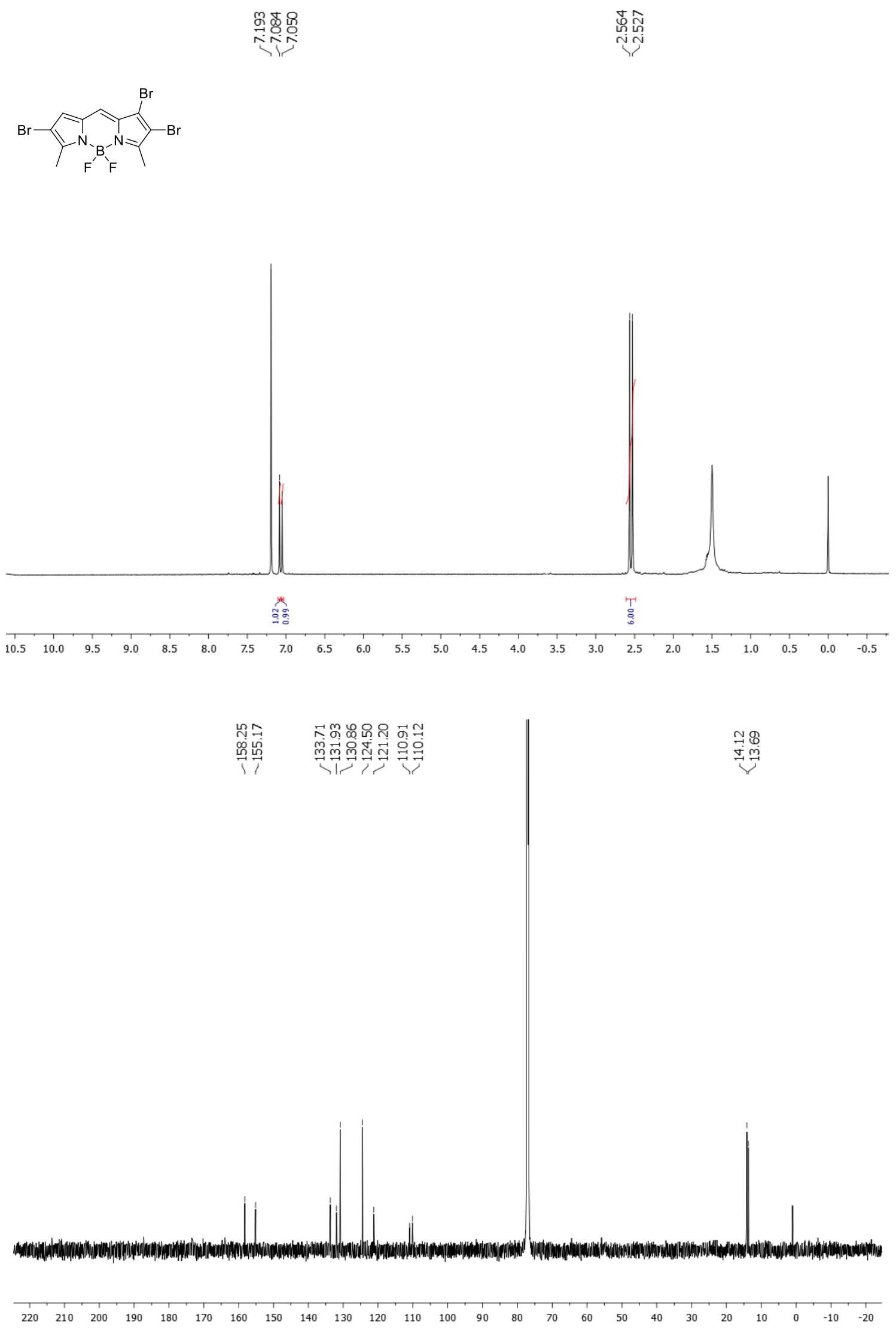
${ }^{1} \mathrm{H}\left(300 \mathrm{MHz}, \mathrm{CDCl}_{3}\right)$ and ${ }^{13} \mathrm{C}\left(75 \mathrm{MHz}, \mathrm{CDCl}_{3}\right)$ NMR spectra of $\mathbf{3 f}$

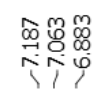

$\underset{\substack{f \\ i}}{\stackrel{F}{0}}$
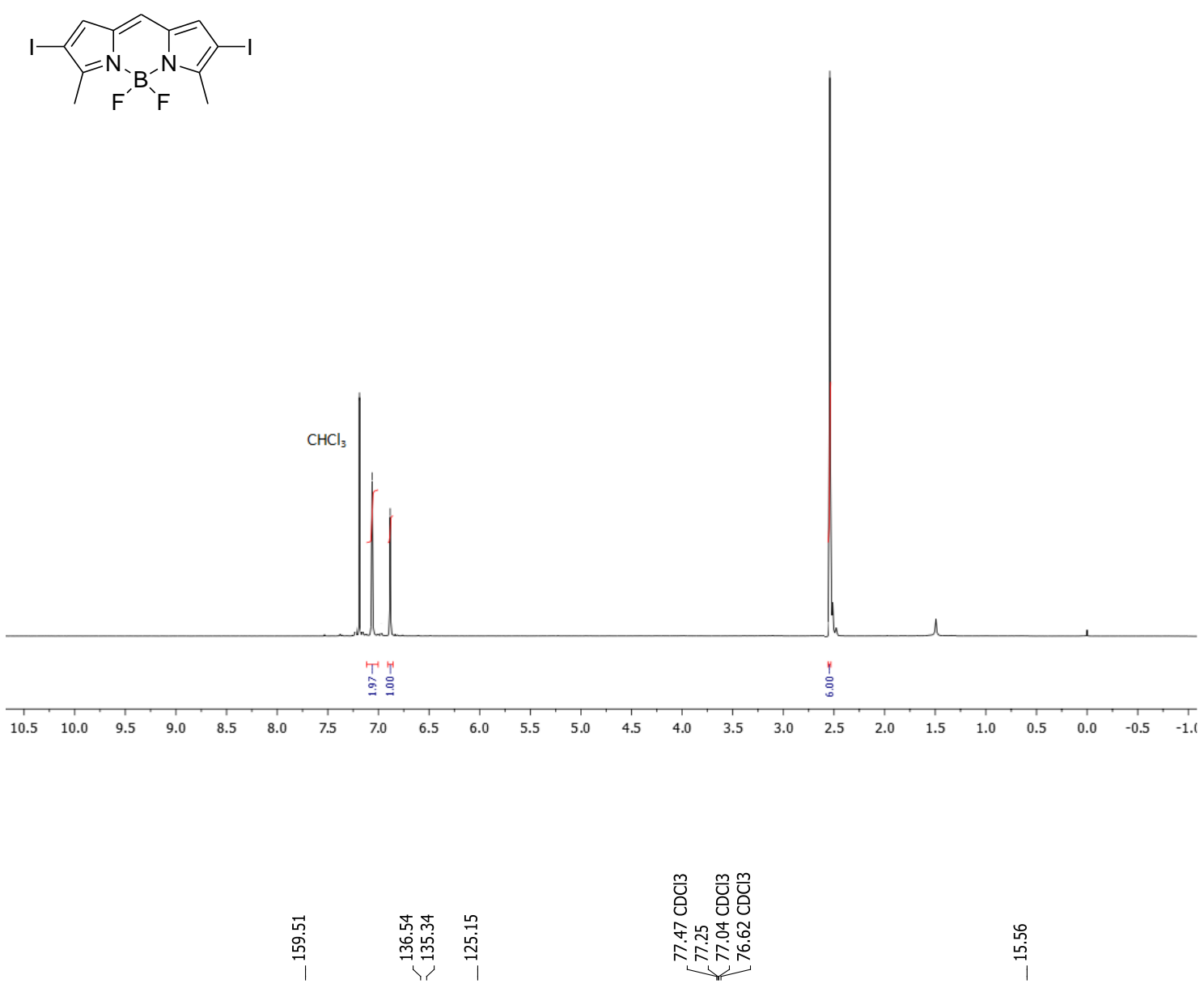

no

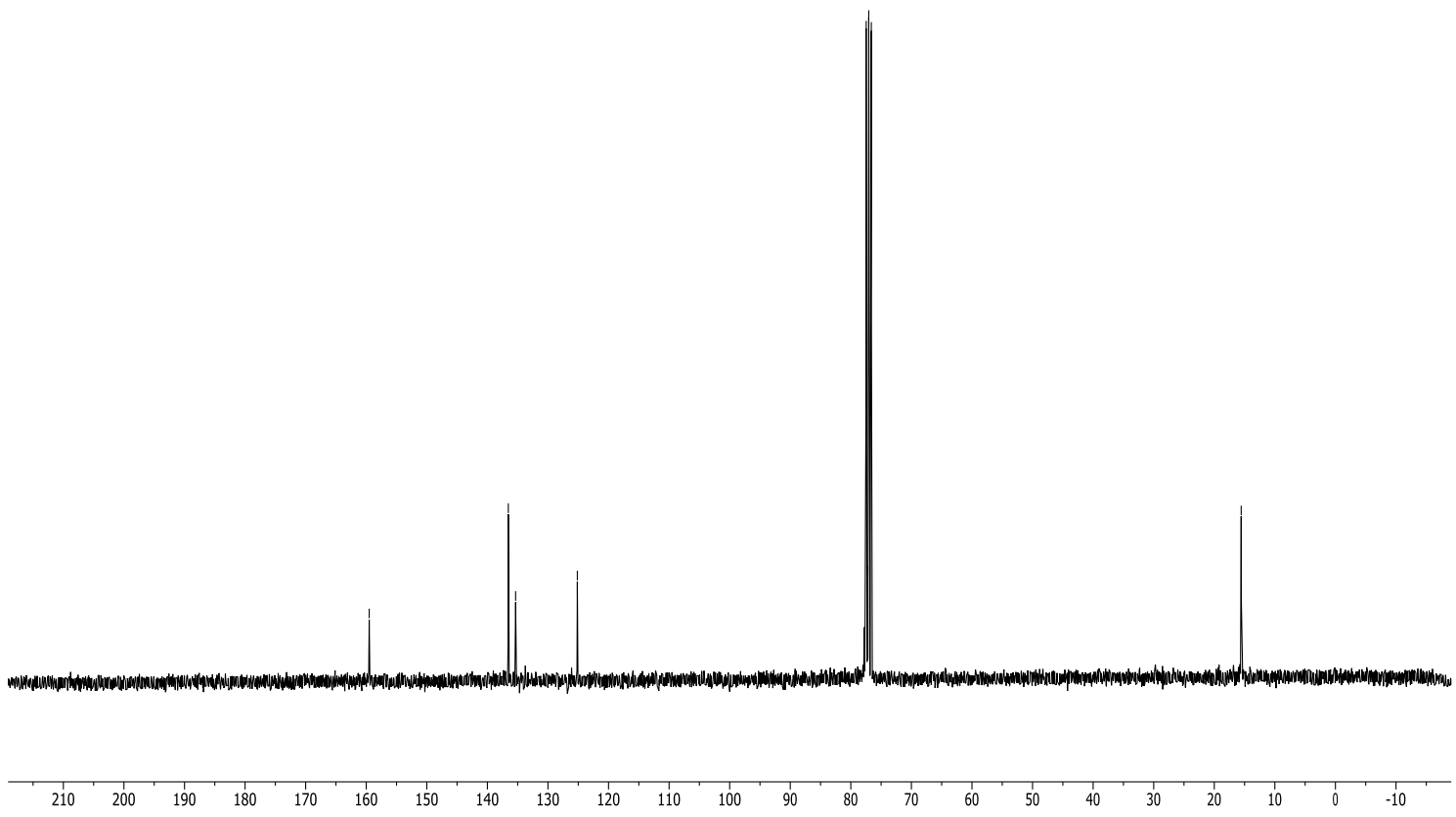

SE 
${ }^{1} \mathrm{H}\left(300 \mathrm{MHz}, \mathrm{CDCl}_{3}\right)$ and ${ }^{13} \mathrm{C}\left(75 \mathrm{MHz}, \mathrm{CDCl}_{3}\right)$ NMR spectra of $\mathbf{3 g}$
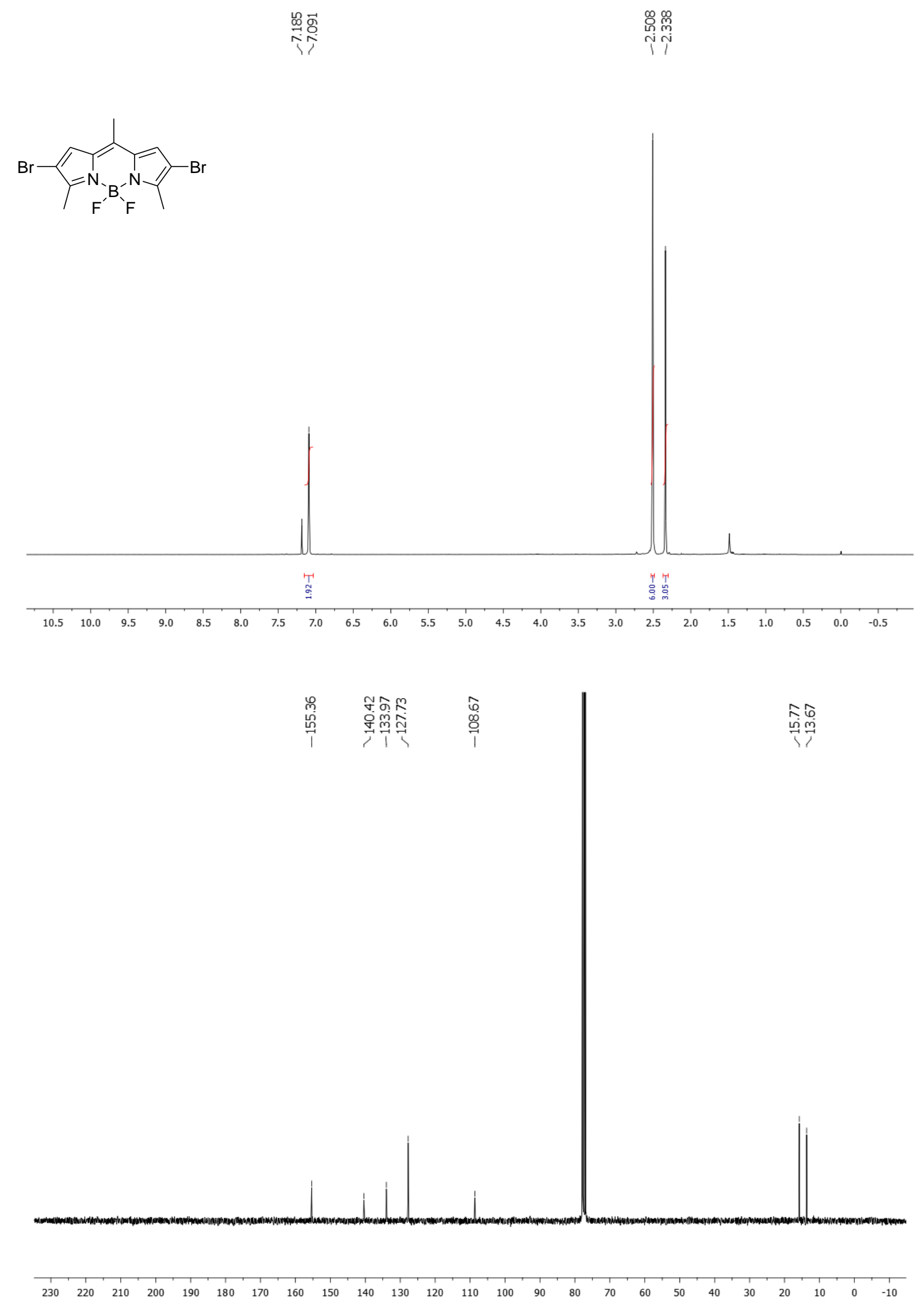
${ }^{1} \mathrm{H}\left(300 \mathrm{MHz}, \mathrm{CDCl}_{3}\right)$ and ${ }^{13} \mathrm{C}\left(75 \mathrm{MHz}, \mathrm{CDCl}_{3}\right)$ NMR spectra of $\mathbf{3 h}$

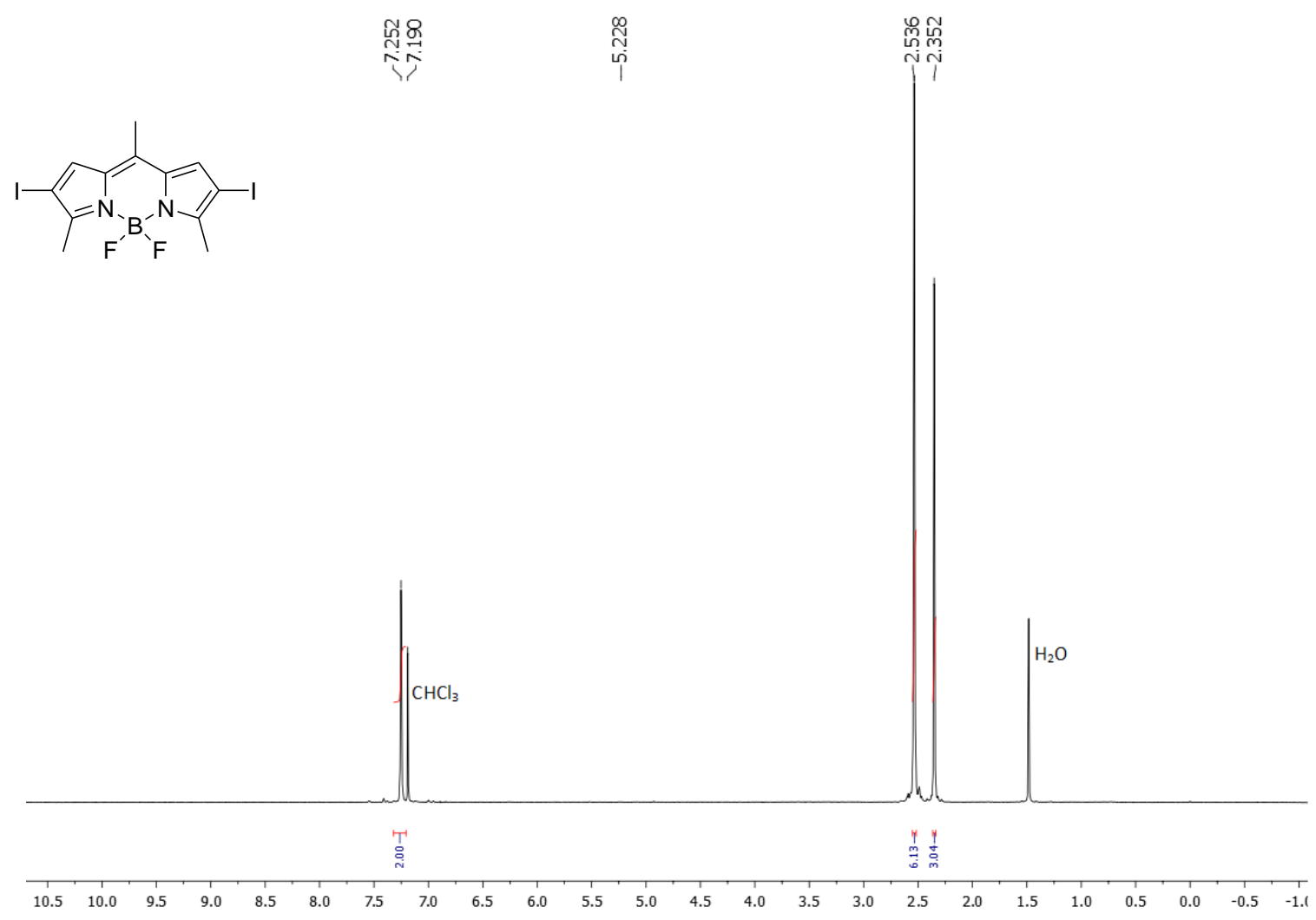

每

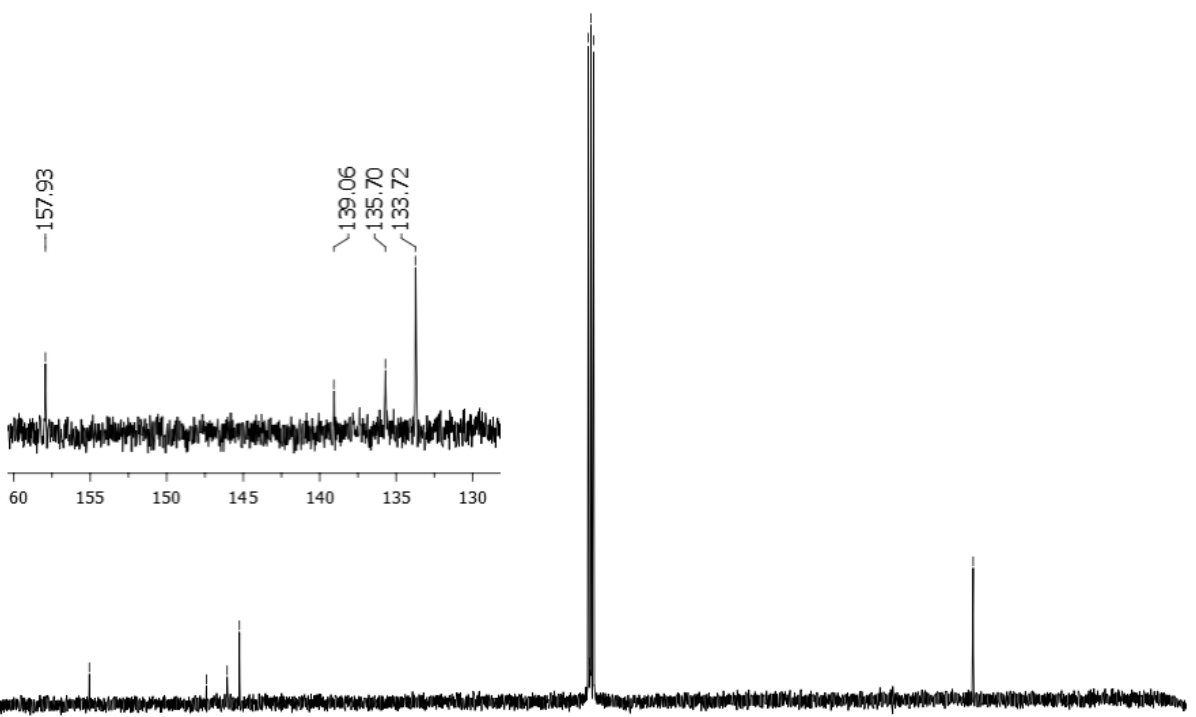

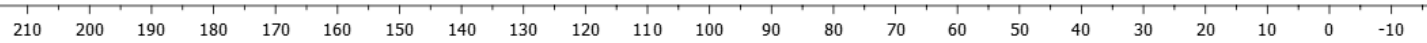


${ }^{1} \mathrm{H}\left(700 \mathrm{MHz}, \mathrm{CDCl}_{3}\right)$ and ${ }^{13} \mathrm{C}\left(176 \mathrm{MHz}, \mathrm{CDCl}_{3}\right)$ NMR spectra of $\mathbf{1 3}$

(c)

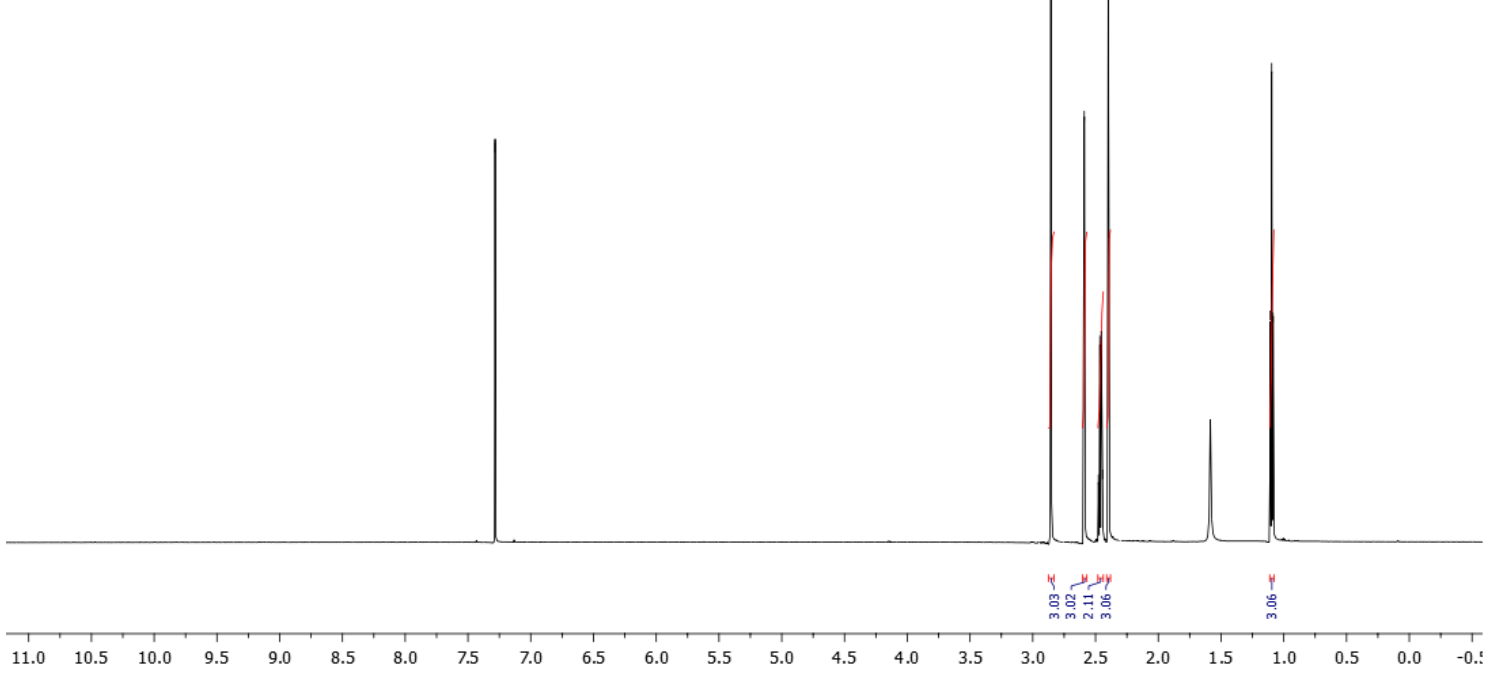

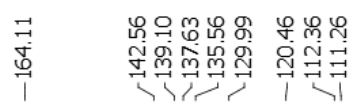

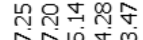

츤대

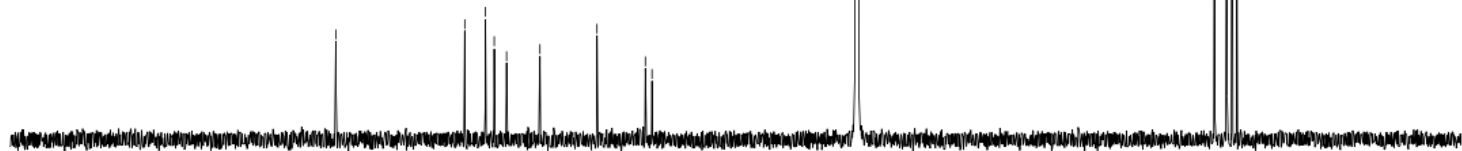

$\begin{array}{lllllllllllll}210 & 200 & 190 & 180 & 170 & 160 & 150 & 140 & 130 & 120 & 110 & 100 & 90\end{array}$ 
${ }^{1} \mathrm{H}\left(300 \mathrm{MHz}, \mathrm{CDCl}_{3}\right)$ and ${ }^{13} \mathrm{C}\left(75 \mathrm{MHz}, \mathrm{CDCl}_{3}\right)$ NMR spectra of 24b

量总兽

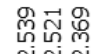

กั่
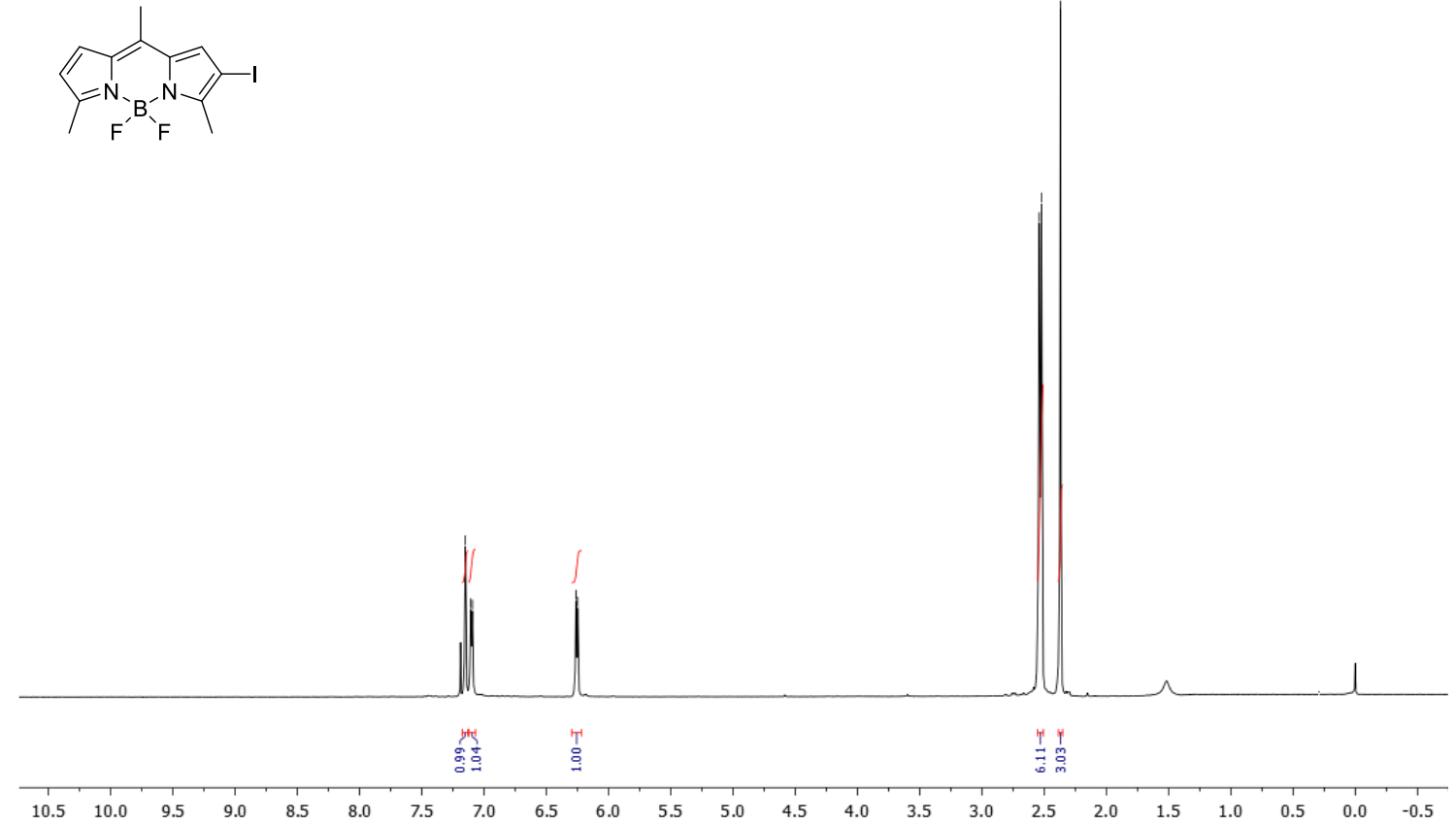

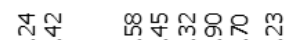

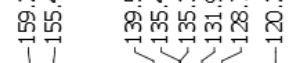

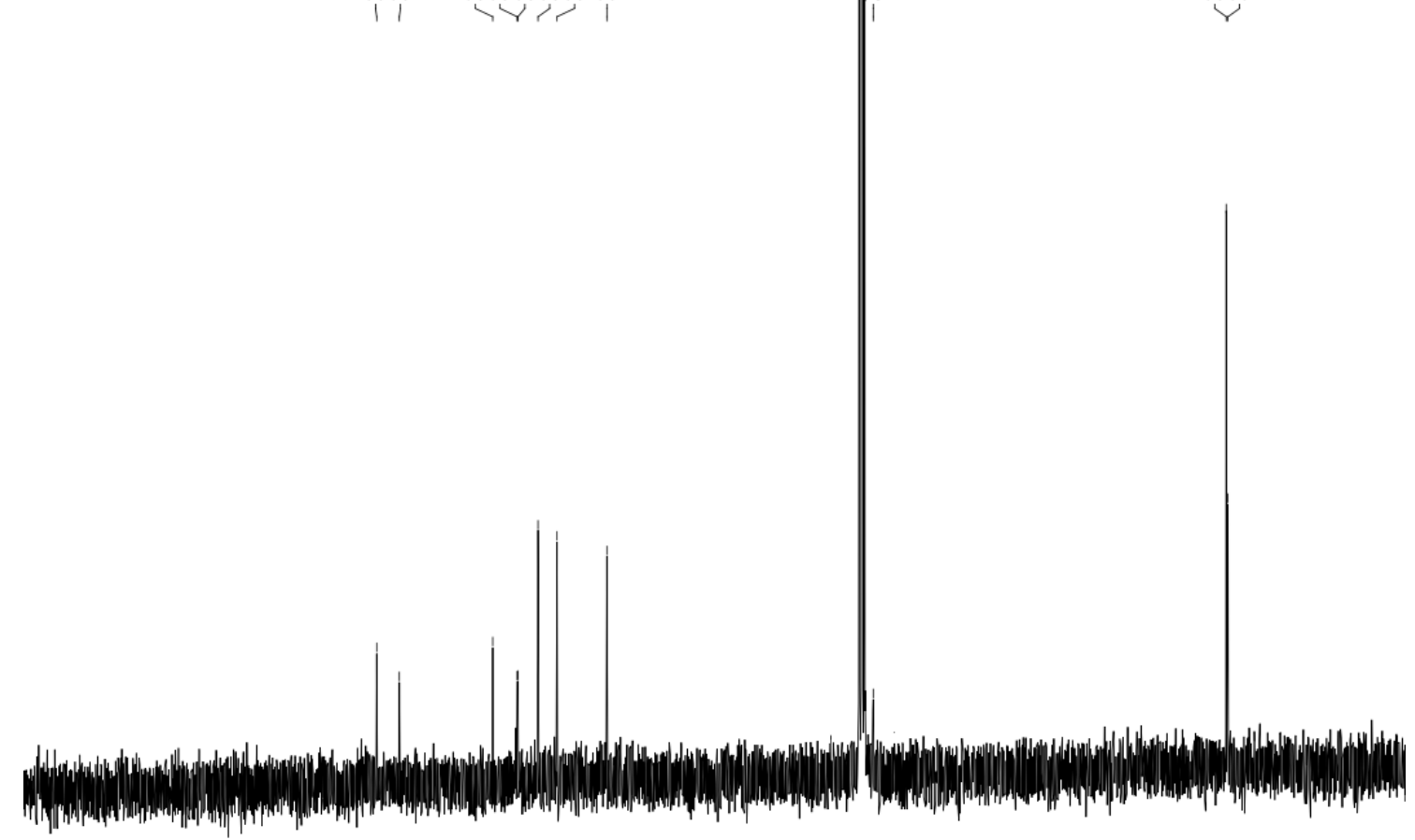

$\begin{array}{llllllllllll}210 & 200 & 190 & 180 & 170 & 160 & 150 & 140 & 130 & 120 & 110 & 100\end{array}$

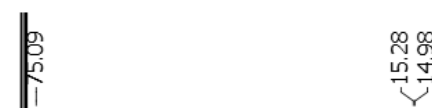


${ }^{1} \mathrm{H}\left(700 \mathrm{MHz}, \mathrm{CDCl}_{3}\right)$ and ${ }^{13} \mathrm{C}\left(176 \mathrm{MHz}, \mathrm{CDCl}_{3}\right)$ NMR spectra of $\mathbf{4 a}$
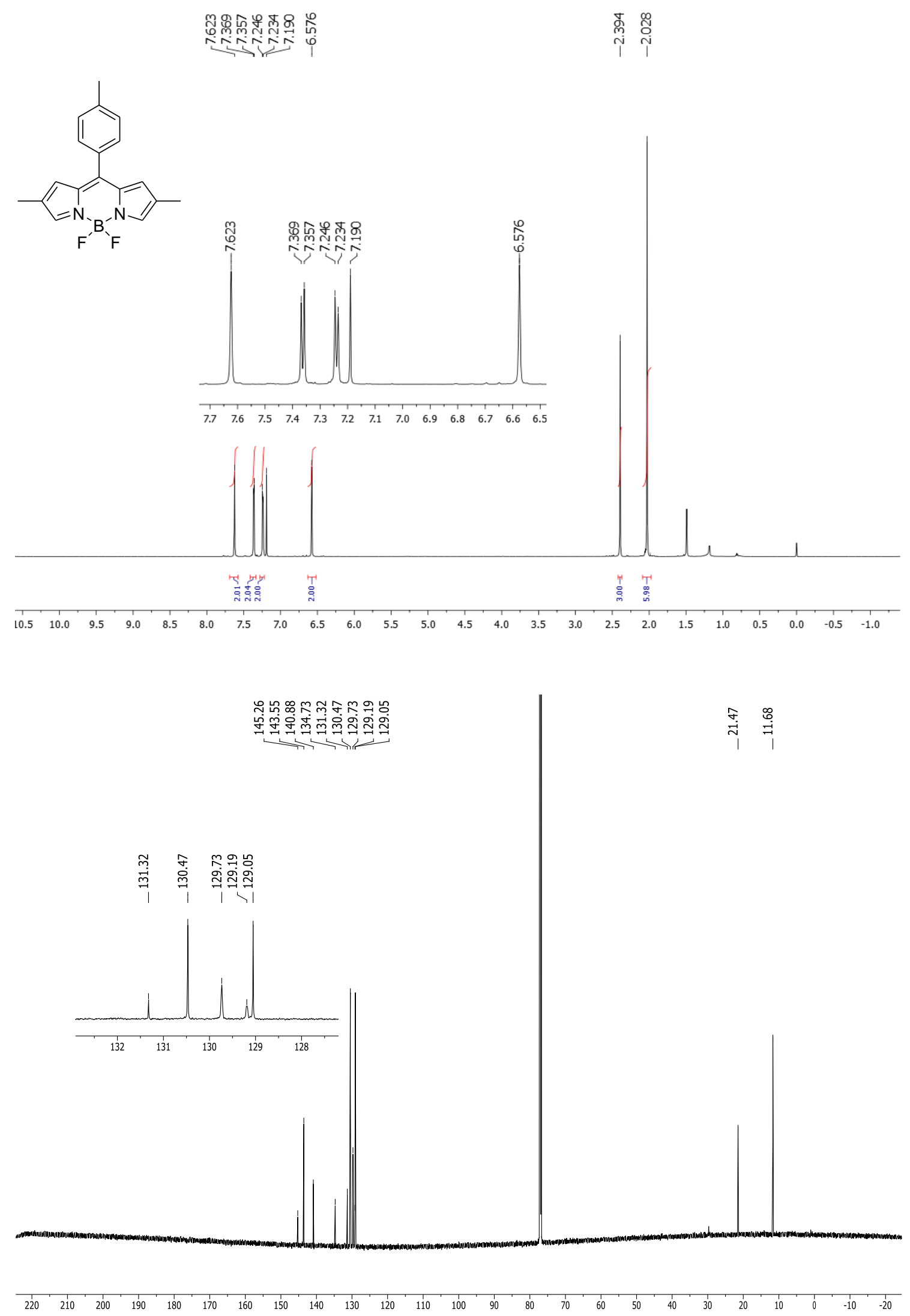
${ }^{1} \mathrm{H}\left(700 \mathrm{MHz}, \mathrm{CDCl}_{3}\right)$ and ${ }^{13} \mathrm{C}\left(176 \mathrm{MHz}, \mathrm{CDCl}_{3}\right)$ NMR spectra of 5a

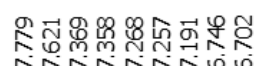

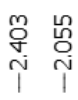

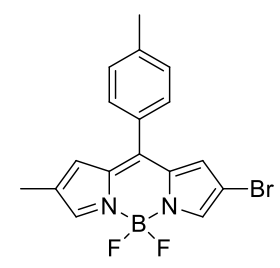

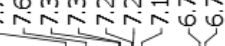

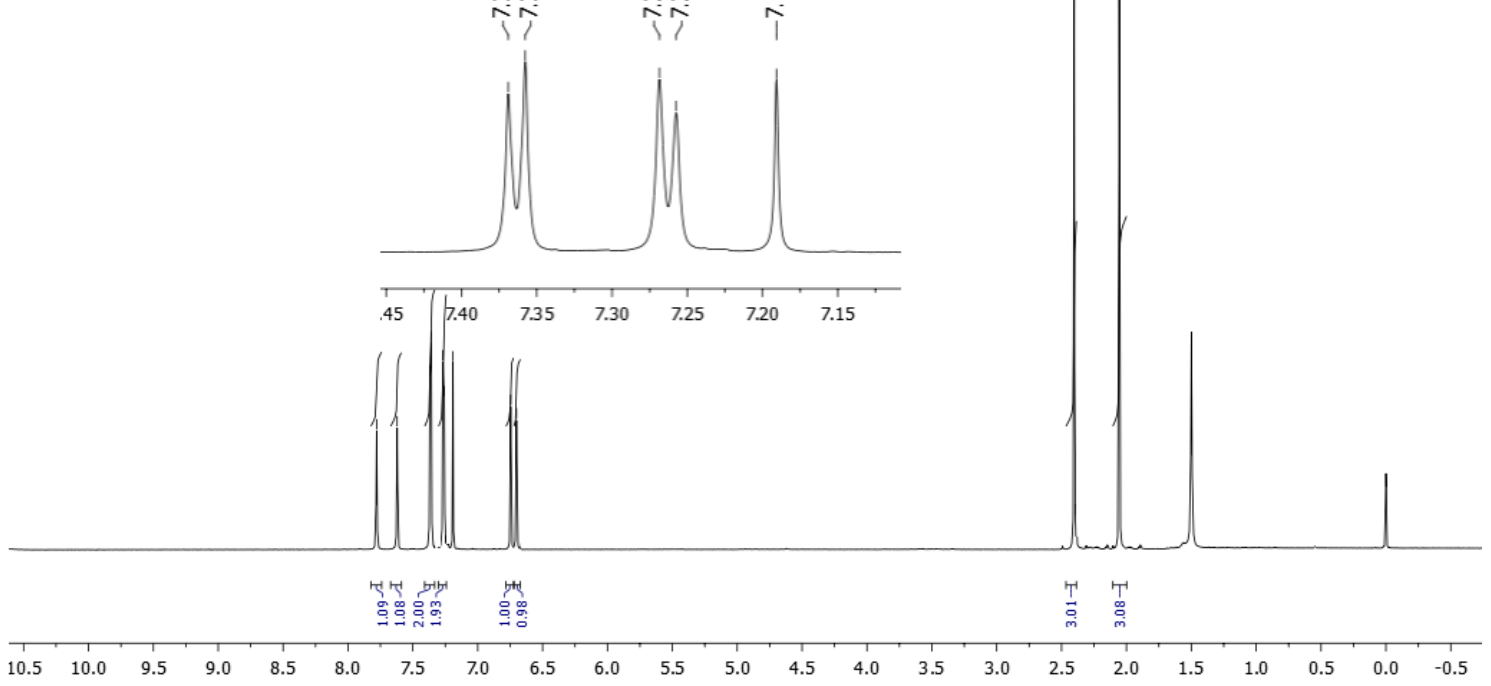

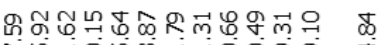

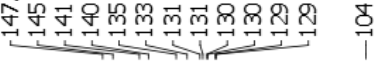

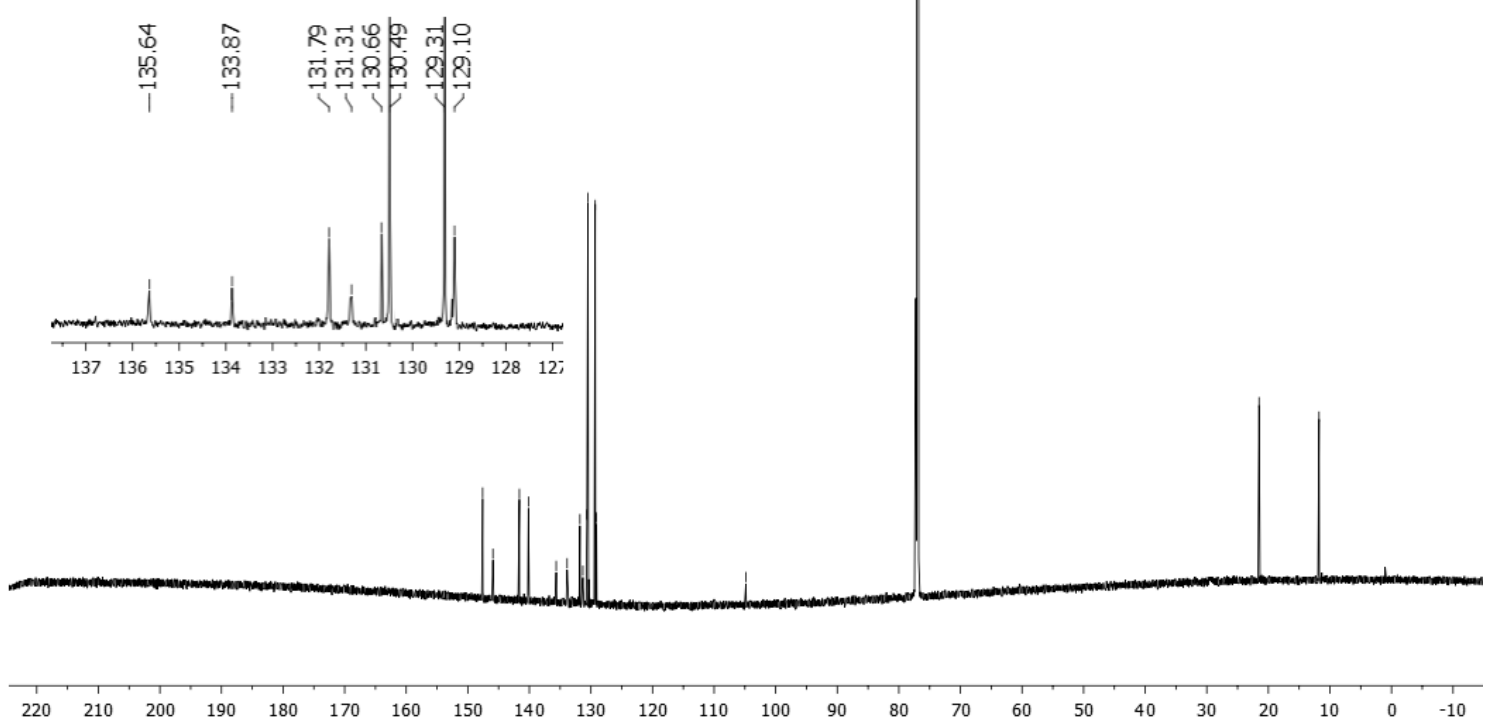


${ }^{1} \mathrm{H}\left(700 \mathrm{MHz}, \mathrm{CDCl}_{3}\right)$ and ${ }^{13} \mathrm{C}\left(176 \mathrm{MHz}, \mathrm{CDCl}_{3}\right) \mathrm{NMR}$ spectra of 6

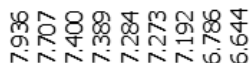

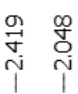
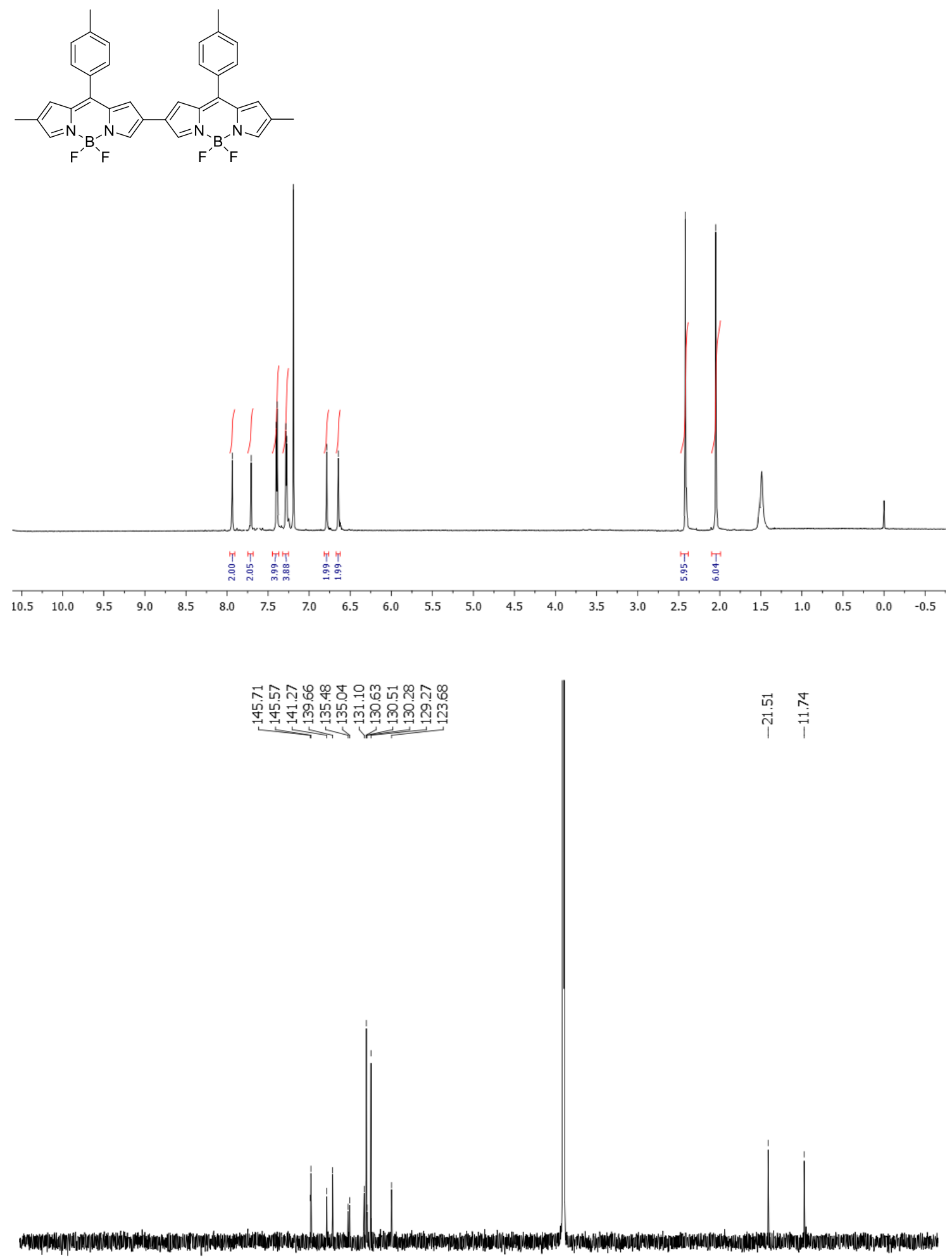

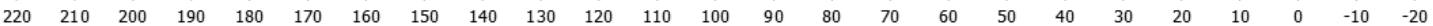


${ }^{1} \mathrm{H}\left(700 \mathrm{MHz}, \mathrm{CDCl}_{3}\right)$ and ${ }^{13} \mathrm{C}\left(176 \mathrm{MHz}, \mathrm{CDCl}_{3}\right)$ NMR spectra of $7 \mathbf{a}$

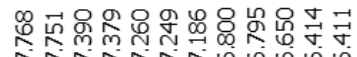

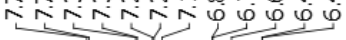

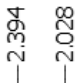

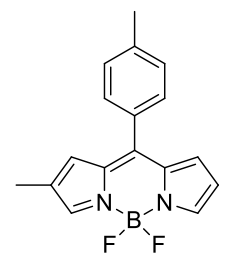

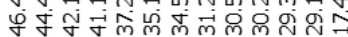

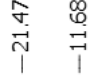

$\begin{array}{llllllllllllll}220 & 210 & 200 & 190 & 180 & 170 & 160 & 150 & 140 & 130 & 120 & 110 & 100 & 90\end{array}$

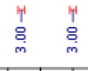

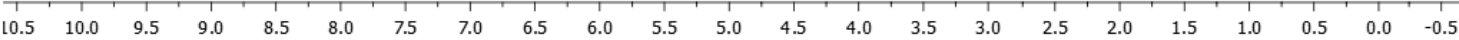

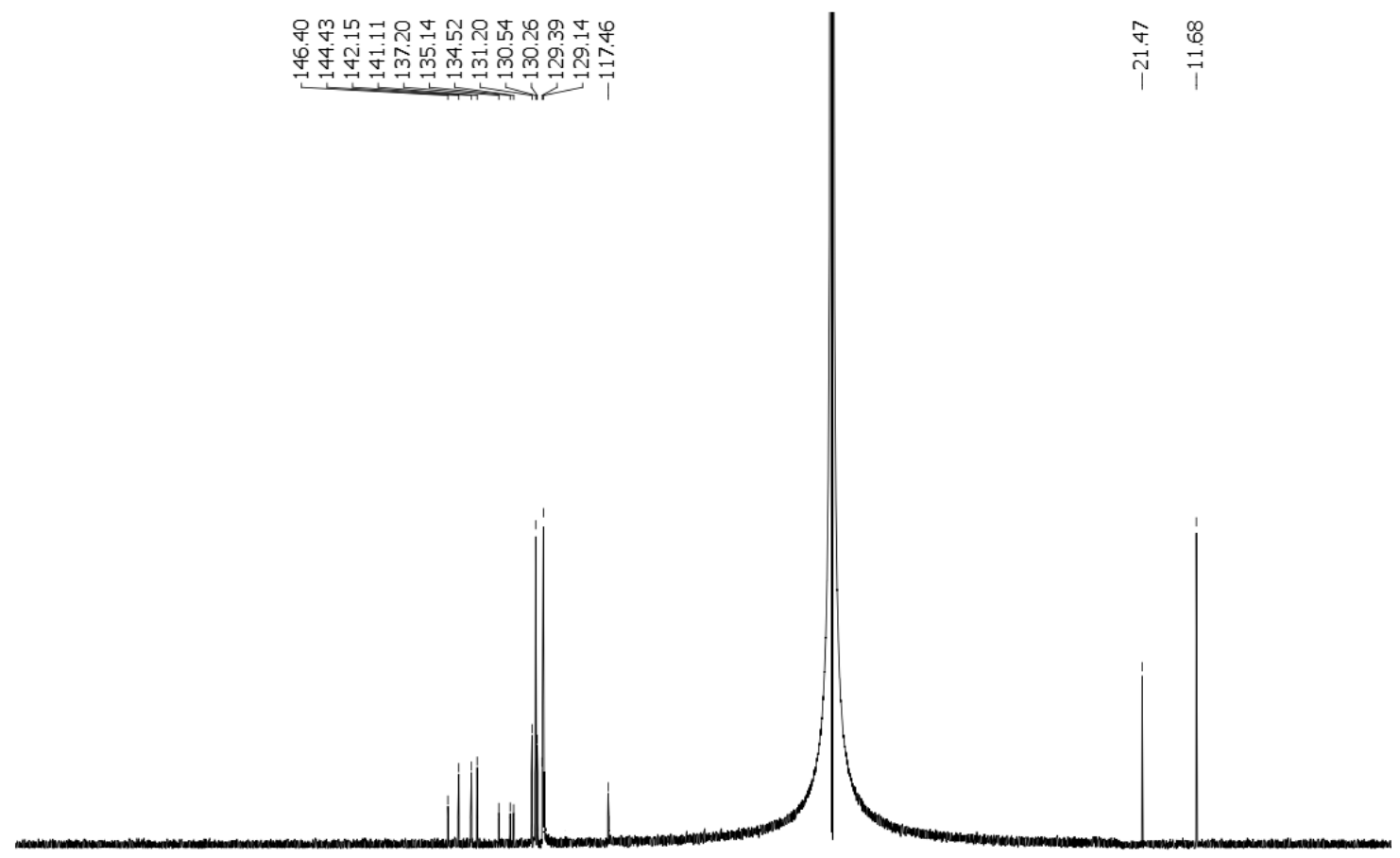


${ }^{1} \mathrm{H}\left(700 \mathrm{MHz}, \mathrm{CDCl}_{3}\right)$ and ${ }^{13} \mathrm{C}\left(176 \mathrm{MHz}, \mathrm{CDCl}_{3}\right)$ NMR spectra of $\mathbf{4 b}$

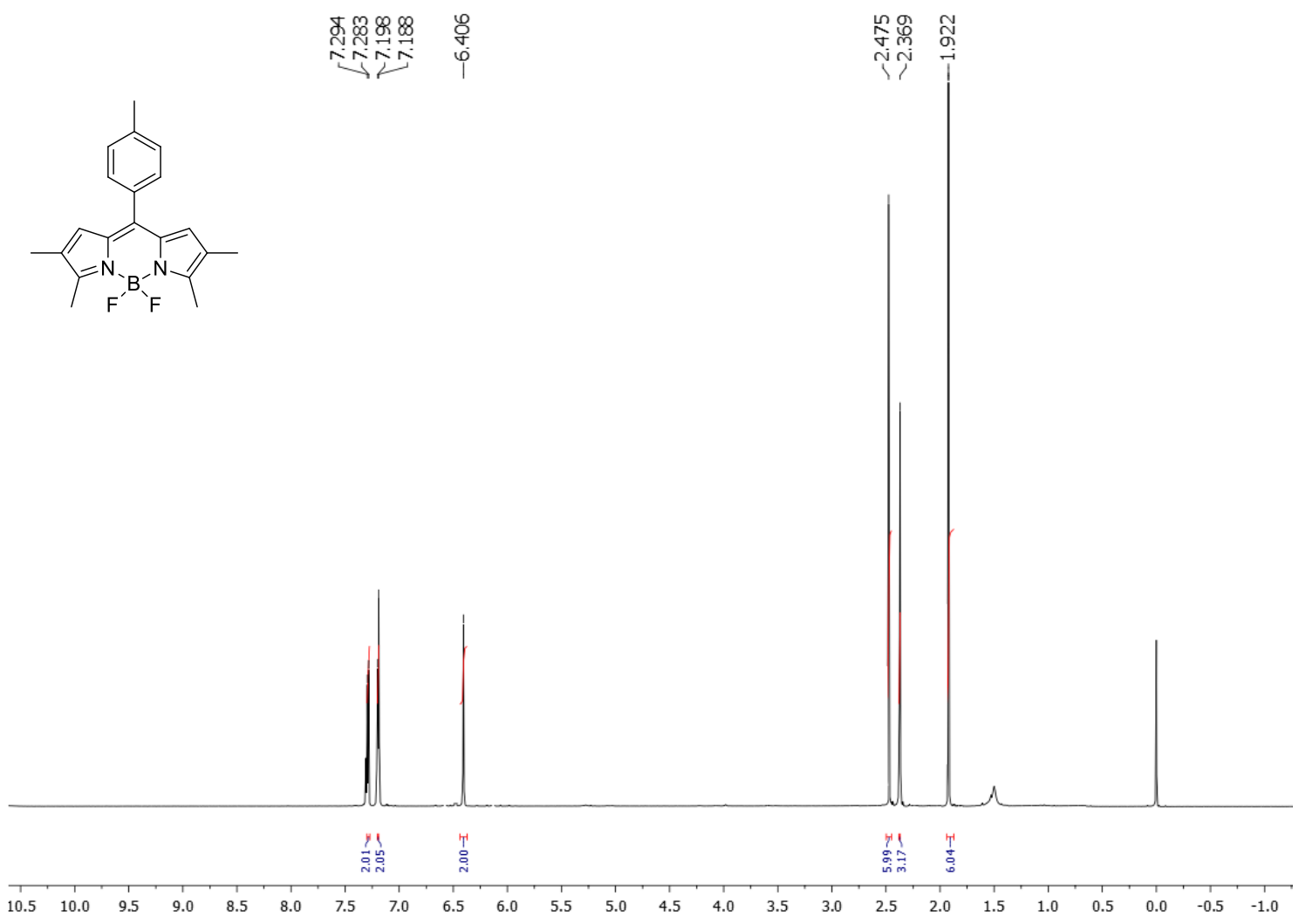

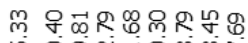

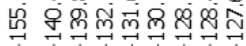

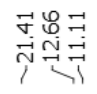

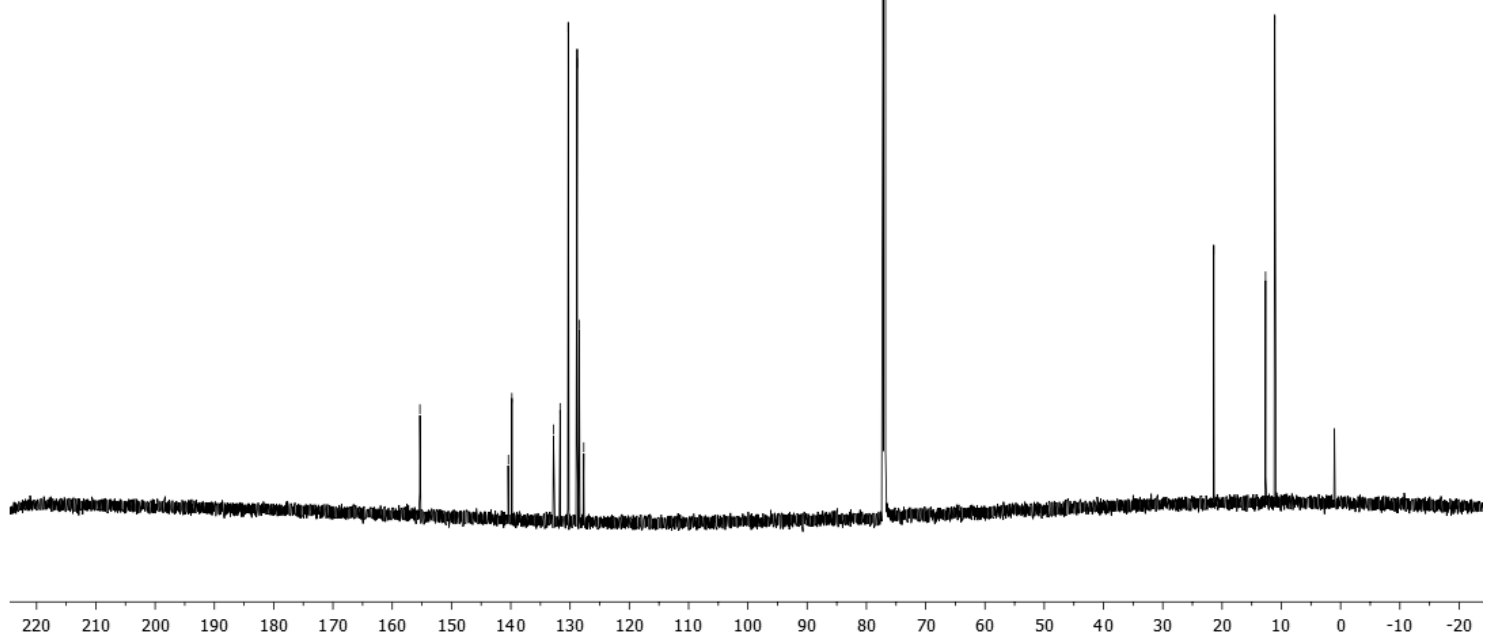


${ }^{1} \mathrm{H}\left(300 \mathrm{MHz}, \mathrm{CDCl}_{3}\right)$ and ${ }^{13} \mathrm{C}\left(75 \mathrm{MHz}, \mathrm{CDCl}_{3}\right)$ NMR spectra of $\mathbf{5 b}$
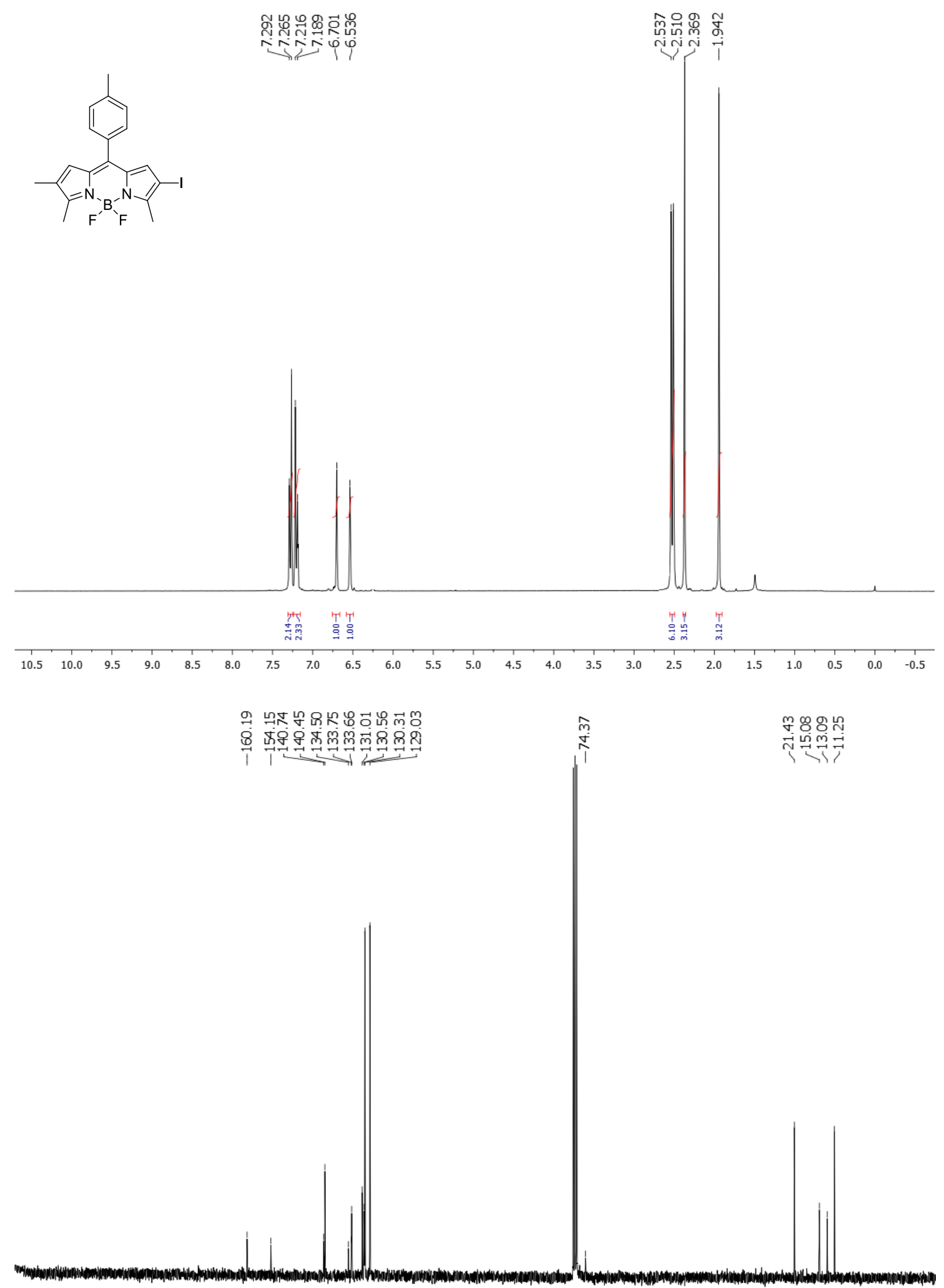

$\begin{array}{llllllllllllllllllllllllllllll}210 & 200 & 190 & 180 & 170 & 160 & 150 & 140 & 130 & 120 & 110 & 100 & 90 & 80 & 70 & 60 & 50 & 40 & 30 & 20 & 10 & 0 & -10\end{array}$ 
${ }^{1} \mathrm{H}\left(700 \mathrm{MHz}, \mathrm{CDCl}_{3}\right)$ and ${ }^{13} \mathrm{C}\left(176 \mathrm{MHz}, \mathrm{CDCl}_{3}\right)$ NMR spectra of $\mathbf{7 b}$

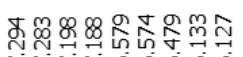

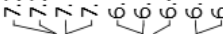

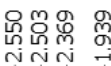
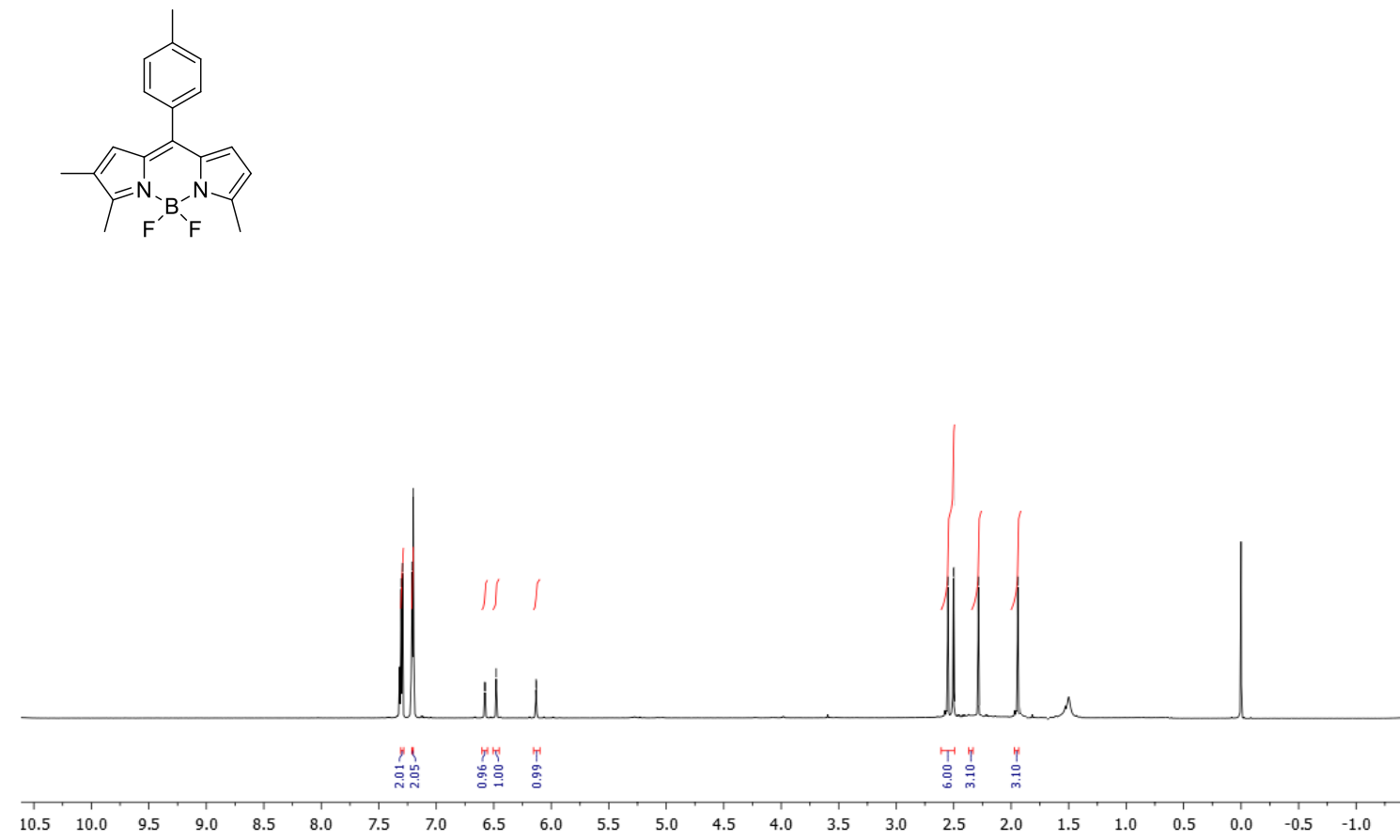

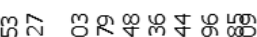

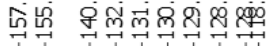

Nivi

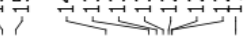

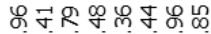

守
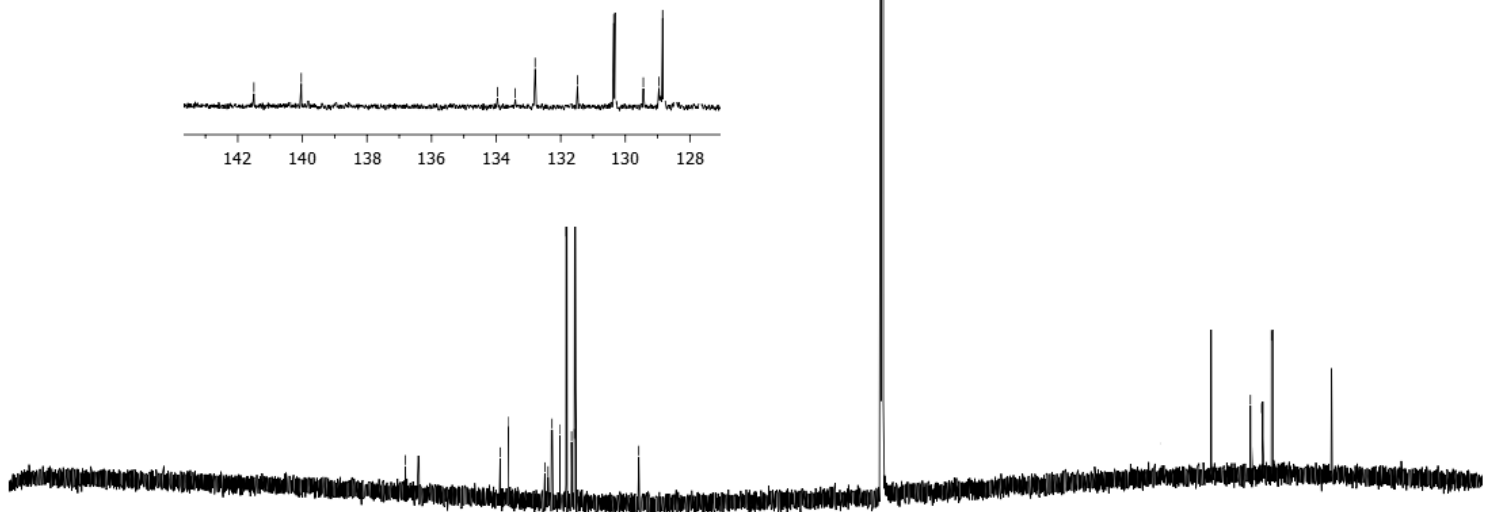

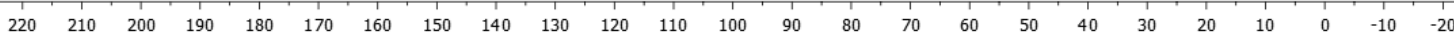


${ }^{1} \mathrm{H}\left(300 \mathrm{MHz}, \mathrm{CDCl}_{3}\right)$ NMR spectrum of known $\mathbf{4} \mathbf{c}^{1}$

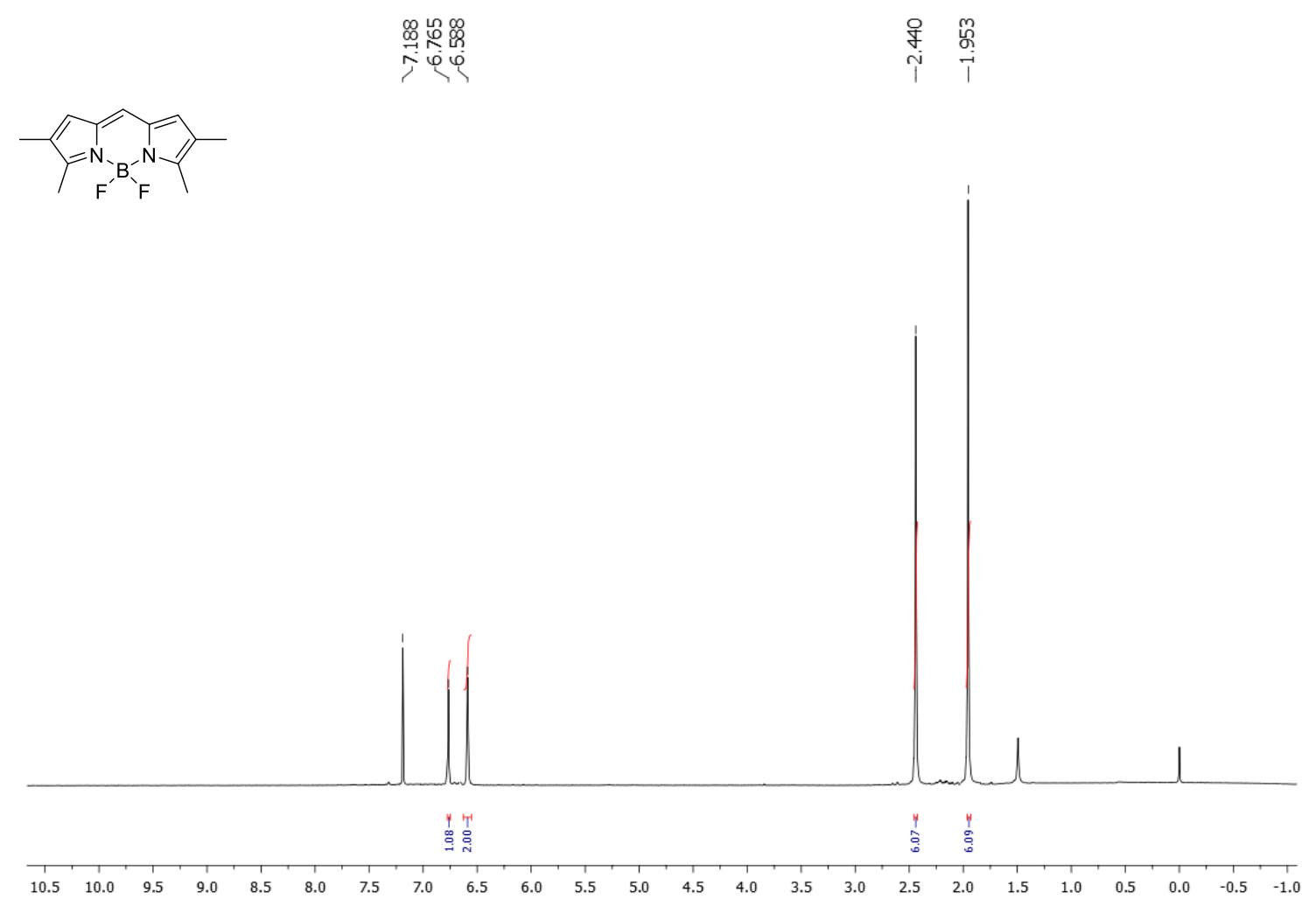

${ }^{1} \mathrm{H}\left(300 \mathrm{MHz}, \mathrm{CDCl}_{3}\right)$ NMR spectrum of known $\mathbf{4} \mathbf{d}^{1}$

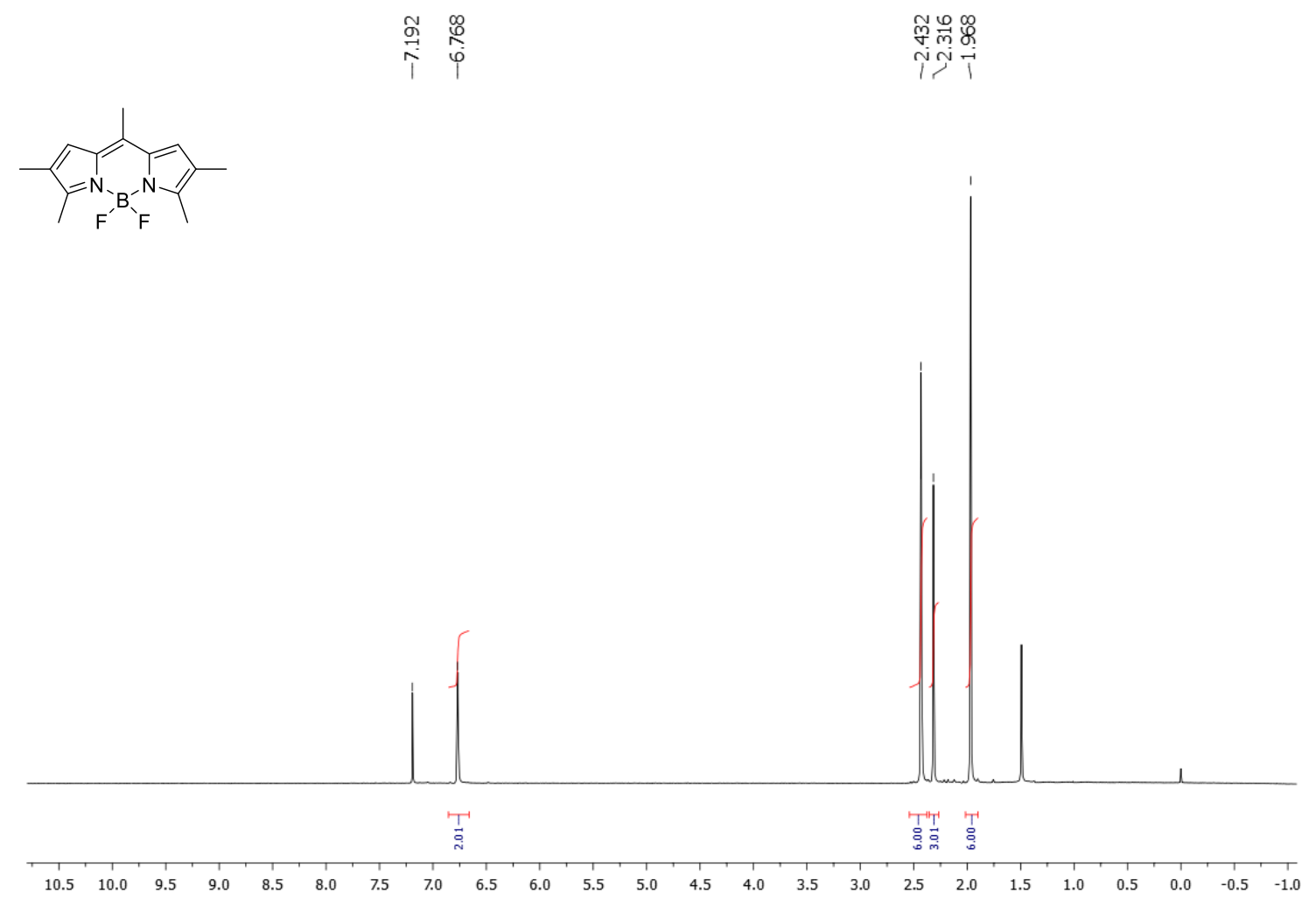


${ }^{1} \mathrm{H}\left(700 \mathrm{MHz}, \mathrm{CDCl}_{3}\right)$ and ${ }^{13} \mathrm{C}\left(176 \mathrm{MHz}, \mathrm{CDCl}_{3}\right)$ NMR spectra of $\mathbf{1 6}$

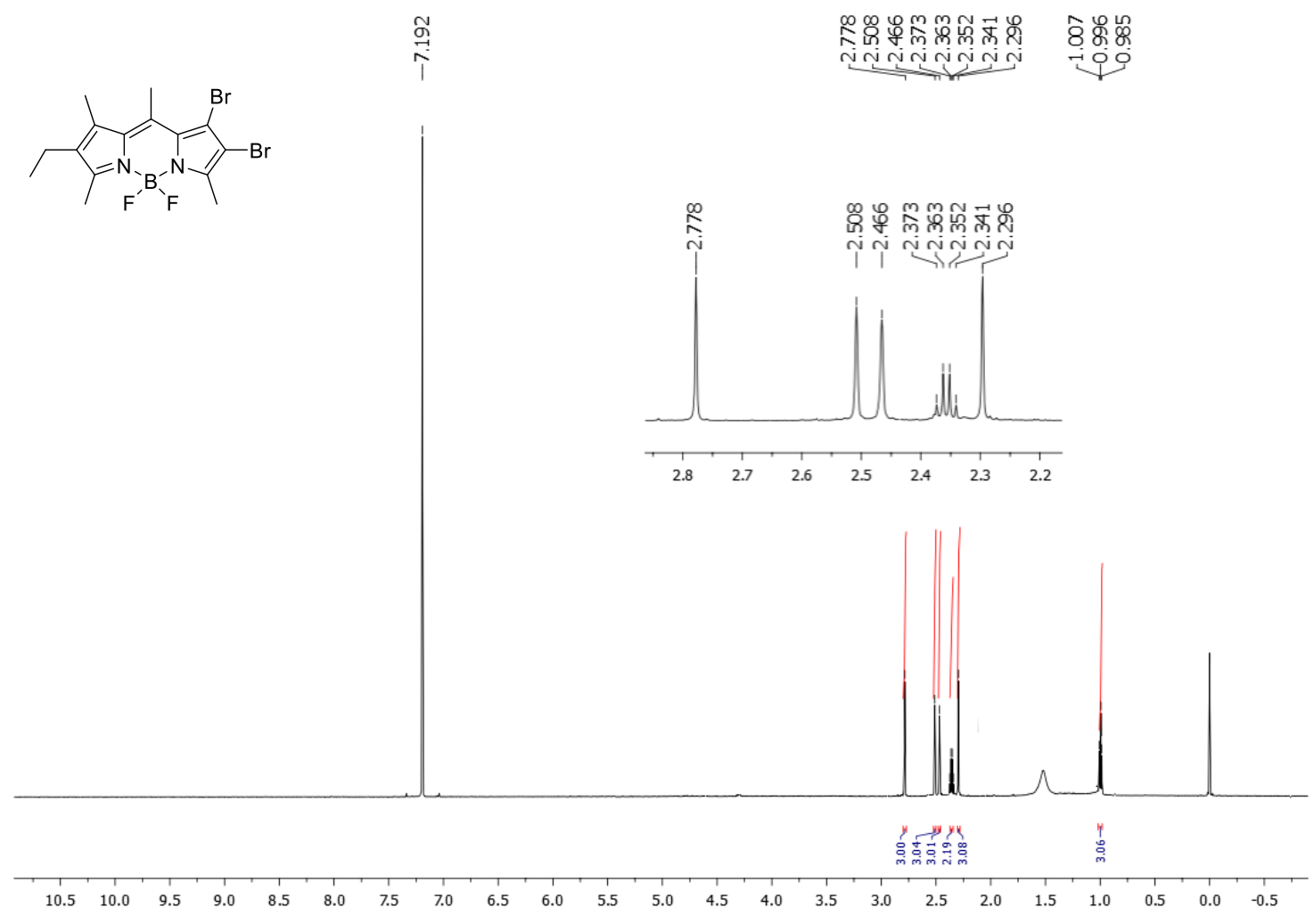

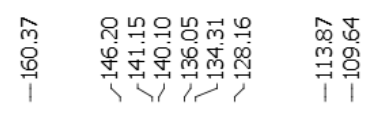

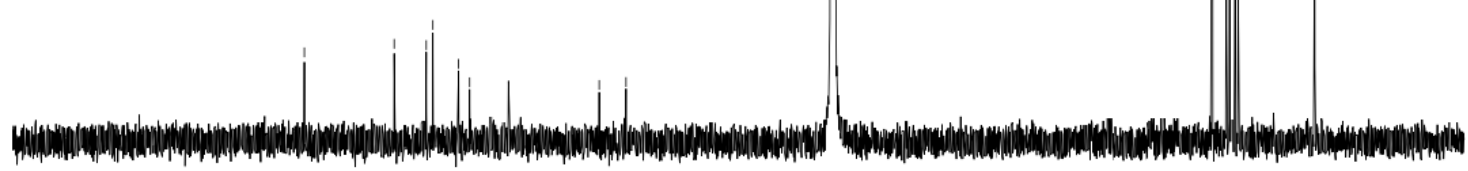

$\begin{array}{llllllllllllllllllllllllll} & 190 & 190 & 180 & 170 & 160 & 150 & 140 & 130 & 120 & 110 & 100 & 90 & 80 & 70 & 60 & 50 & 40 & 30 & 20 & 10 & 0 & -10 & -20\end{array}$ 
${ }^{1} \mathrm{H}\left(700 \mathrm{MHz}, \mathrm{CDCl}_{3}\right)$ and ${ }^{13} \mathrm{C}\left(176 \mathrm{MHz}, \mathrm{CDCl}_{3}\right)$ NMR spectra of $\mathbf{1 7}$
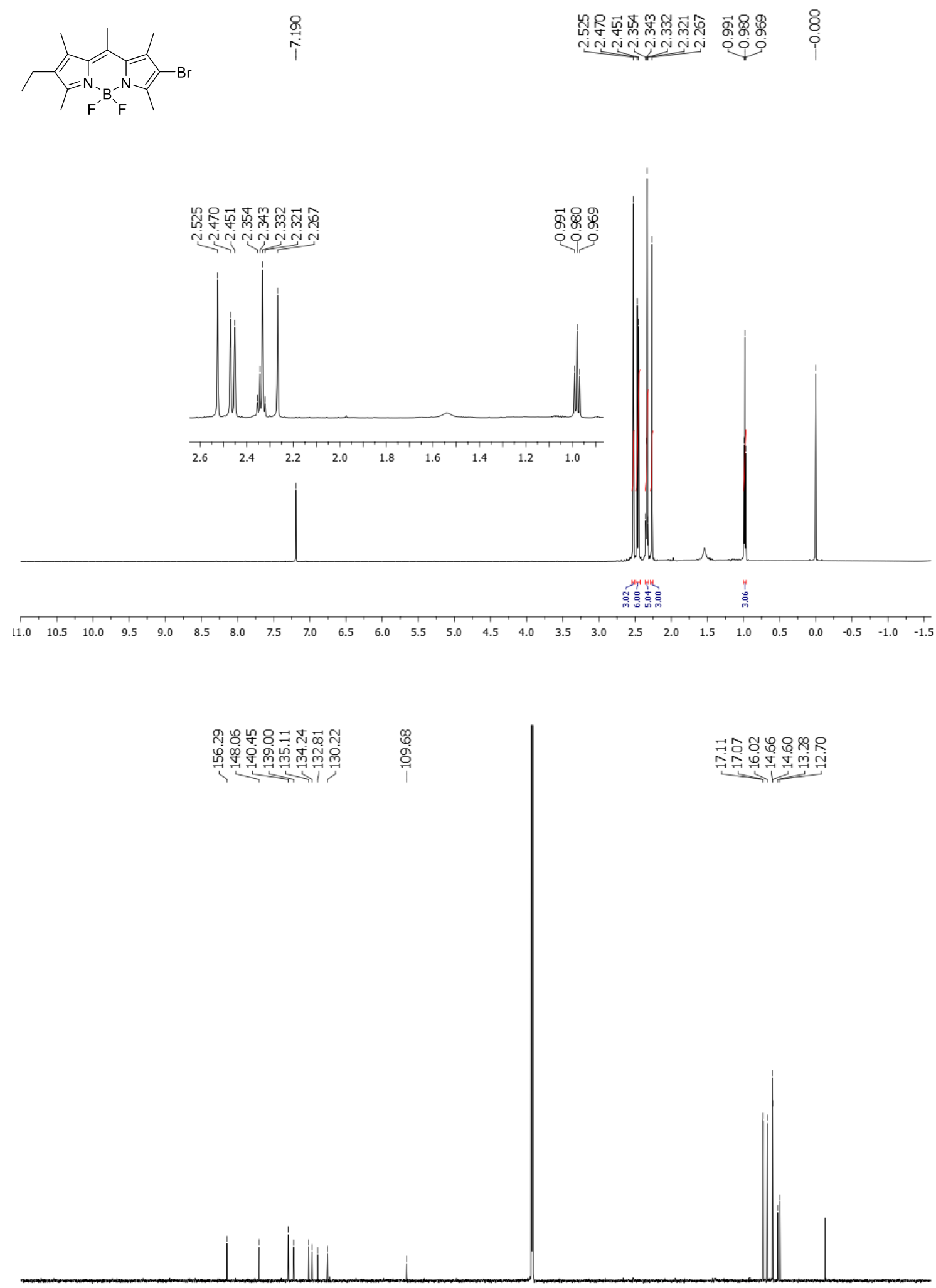

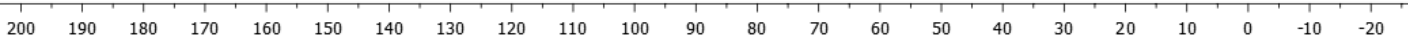


${ }^{1} \mathrm{H}\left(700 \mathrm{MHz}, \mathrm{CDCl}_{3}\right)$ and ${ }^{13} \mathrm{C}\left(176 \mathrm{MHz}, \mathrm{CDCl}_{3}\right)$ NMR spectra of 18
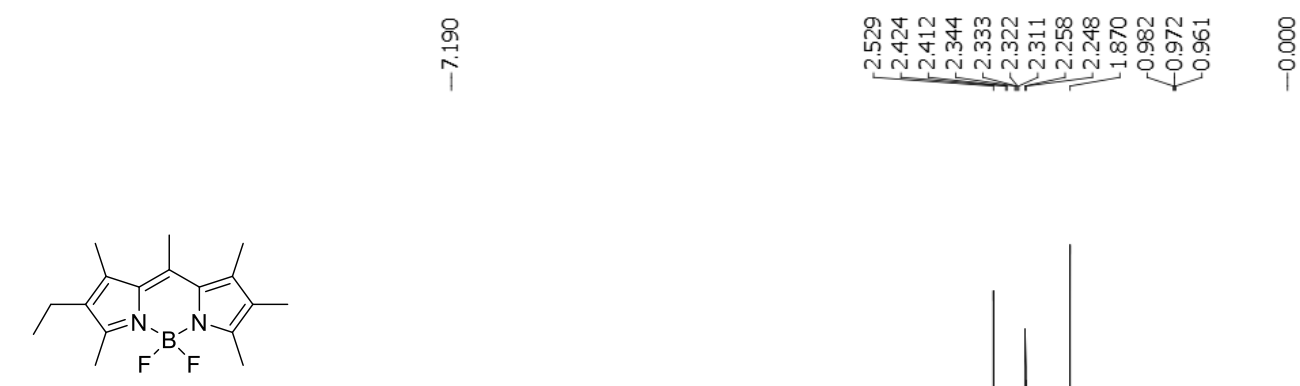

8

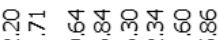

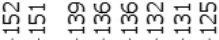

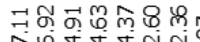

든
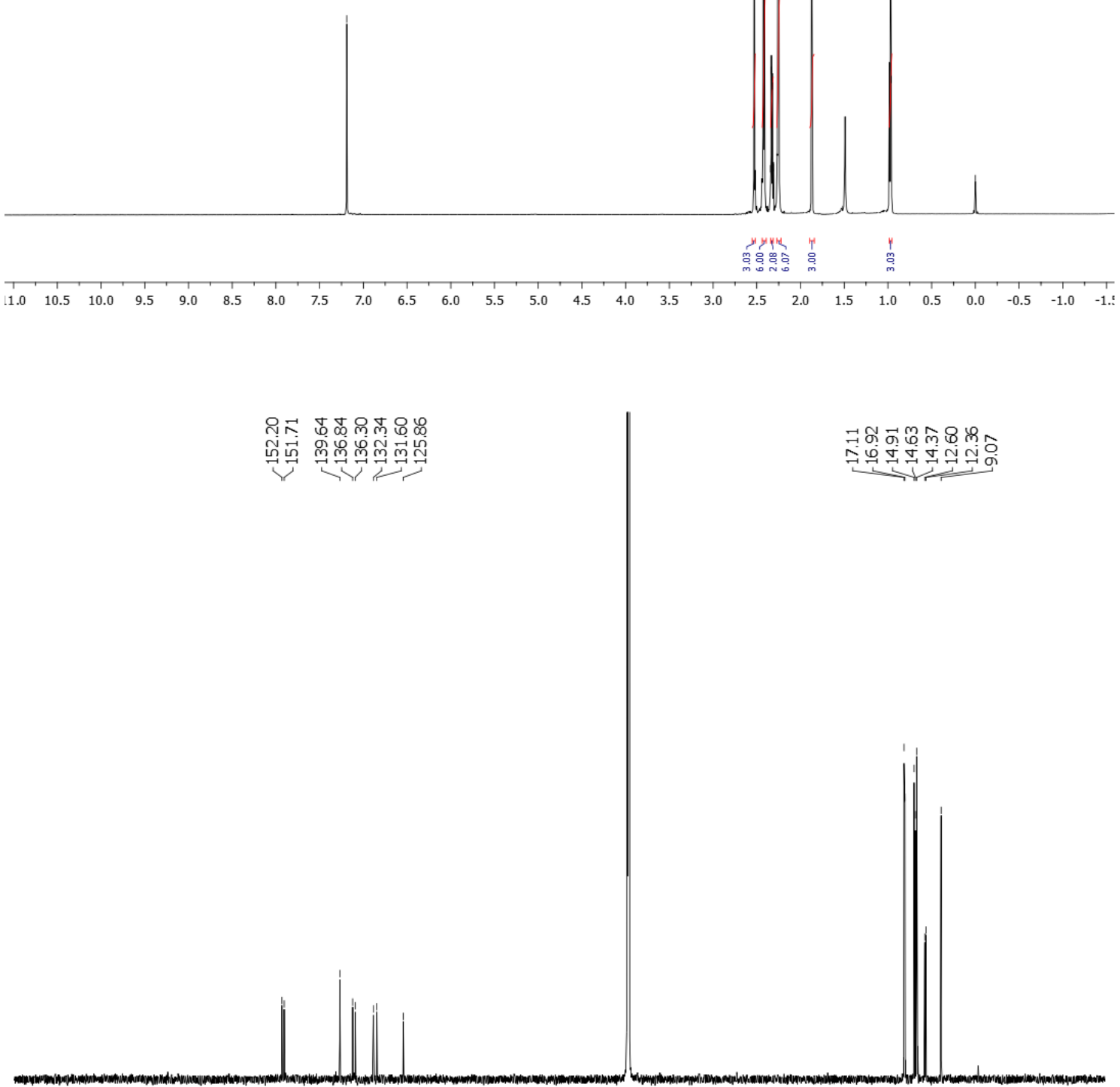

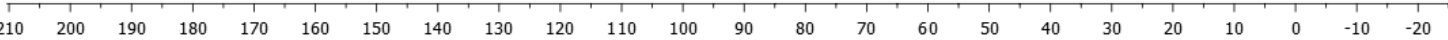


${ }^{1} \mathrm{H}\left(700 \mathrm{MHz}, \mathrm{CDCl}_{3}\right)$ and ${ }^{13} \mathrm{C}\left(176 \mathrm{MHz}, \mathrm{CDCl}_{3}\right)$ NMR spectra of $\mathbf{1 9}$
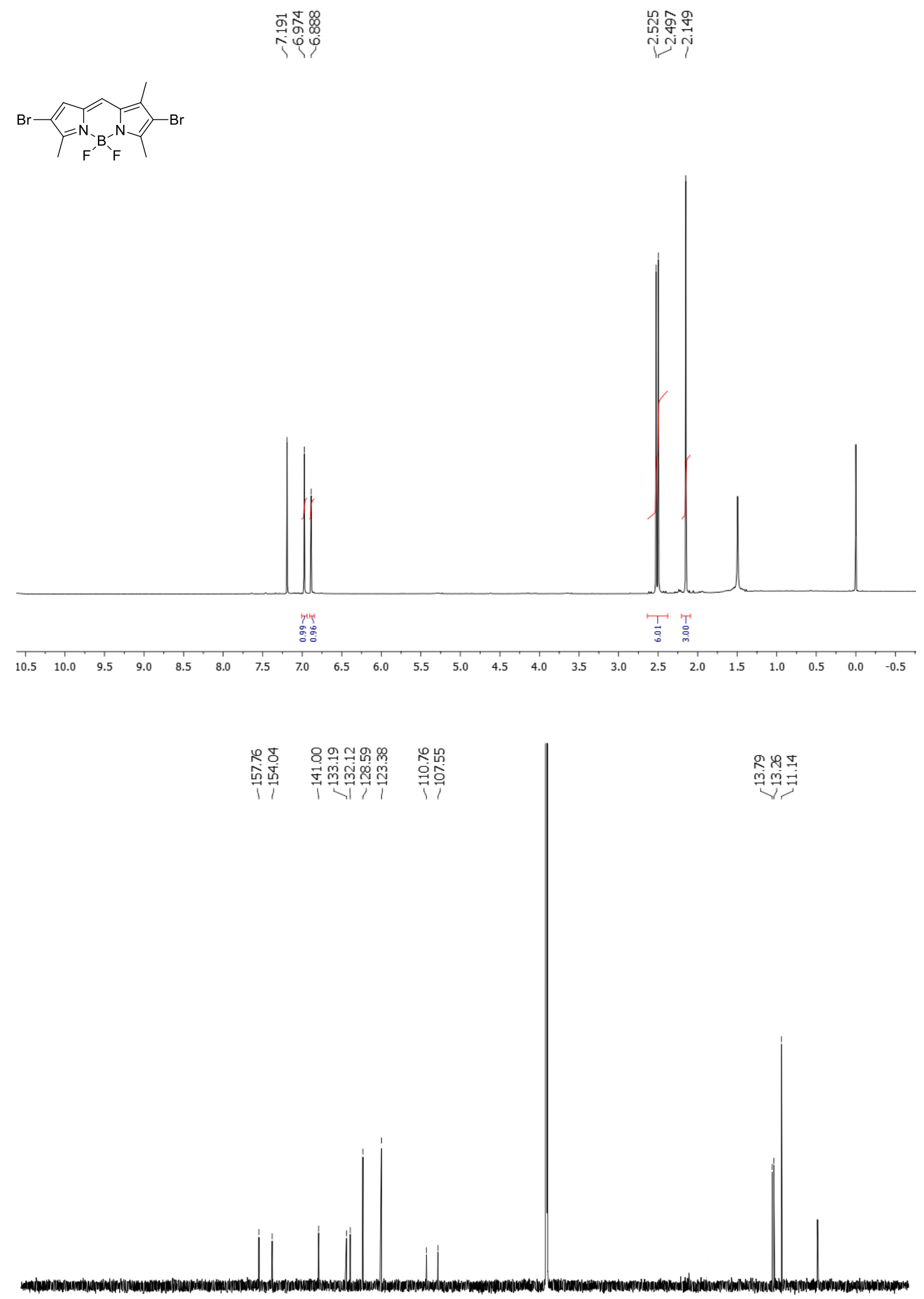

$\begin{array}{llllllllllllllllllllllllll} & 1 \\ 220 & 210 & 200 & 190 & 180 & 170 & 160 & 150 & 140 & 130 & 120 & 110 & 100 & 90 & 80 & 70 & 60 & 50 & 40 & 30 & 20 & 10 & 0 & -10 & -20\end{array}$ 
${ }^{1} \mathrm{H}\left(700 \mathrm{MHz}, \mathrm{CDCl}_{3}\right)$ and ${ }^{13} \mathrm{C}\left(176 \mathrm{MHz}, \mathrm{CDCl}_{3}\right)$ NMR spectra of 20

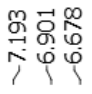

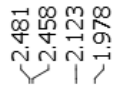

Pr

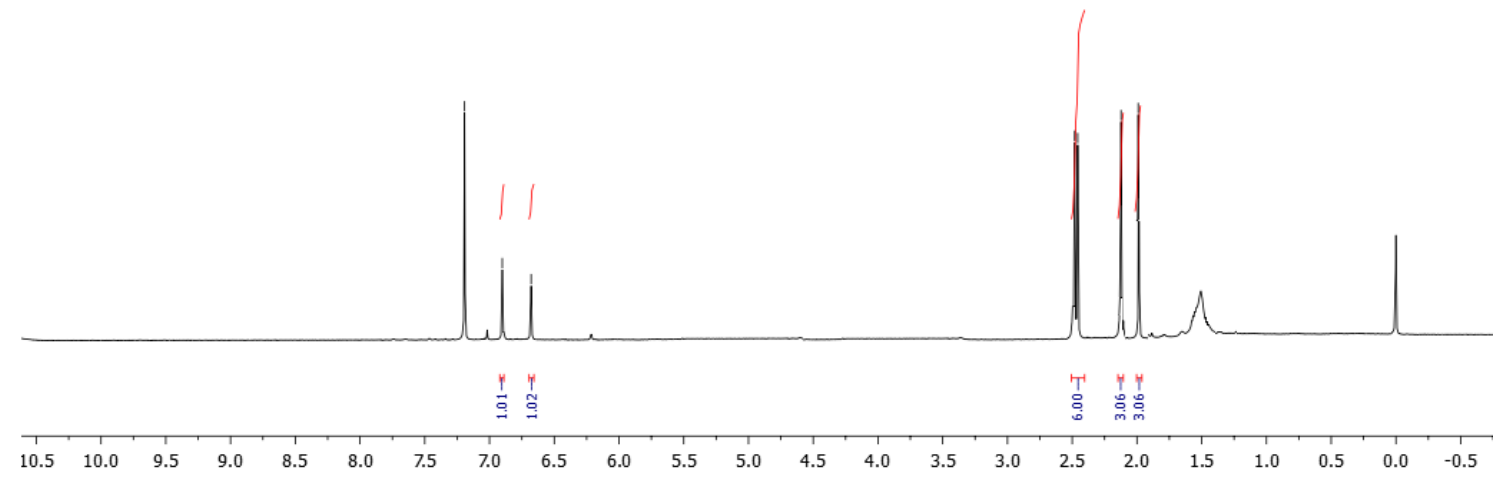

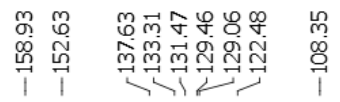

চু ূূঙ

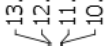

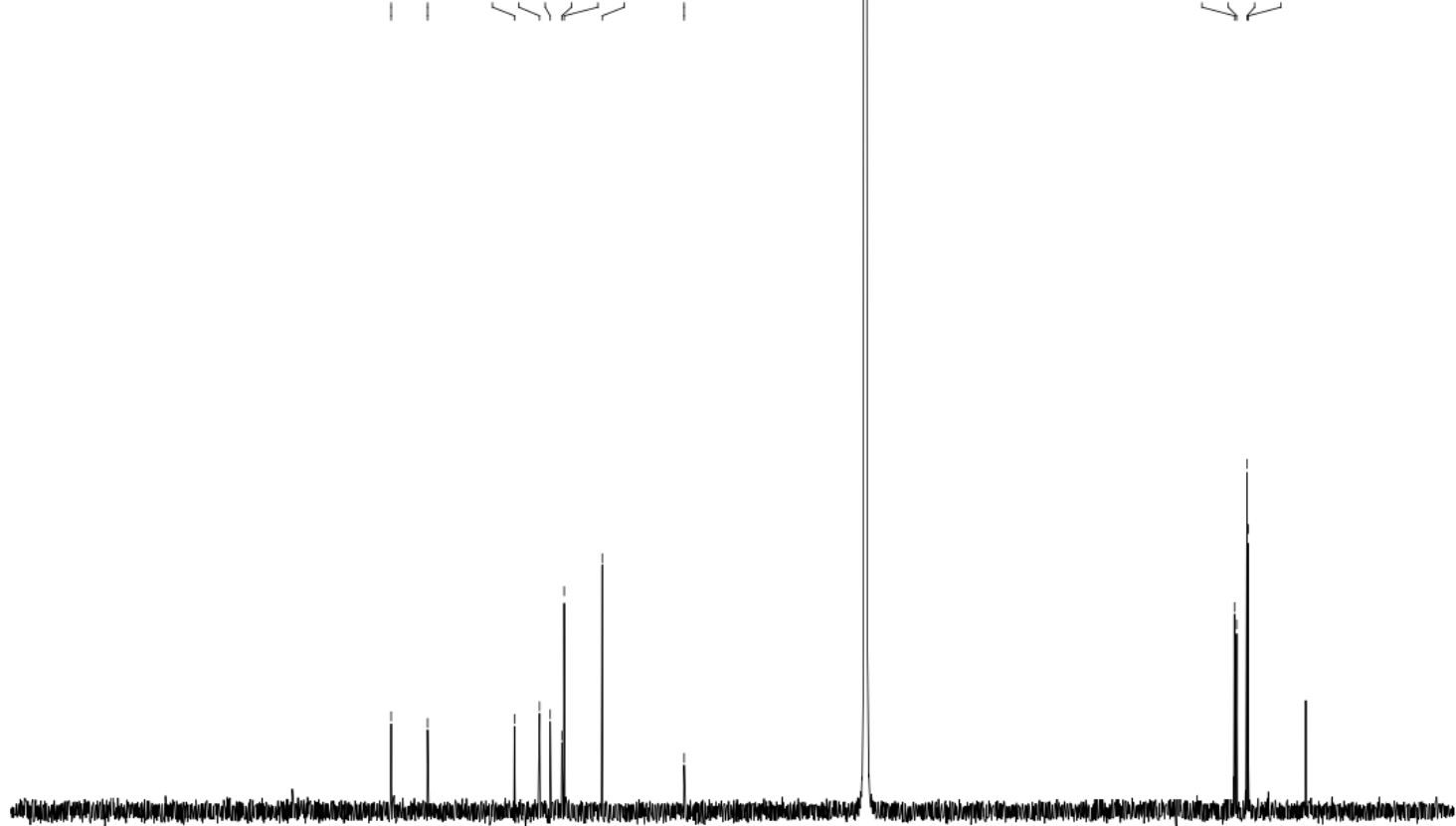

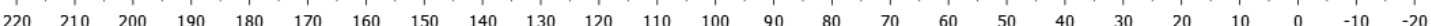


${ }^{1} \mathrm{H}\left(300 \mathrm{MHz}, \mathrm{CDCl}_{3}\right)$ and ${ }^{13} \mathrm{C}\left(75 \mathrm{MHz}, \mathrm{CDCl}_{3}\right)$ NMR spectra of $\mathbf{2 1}$
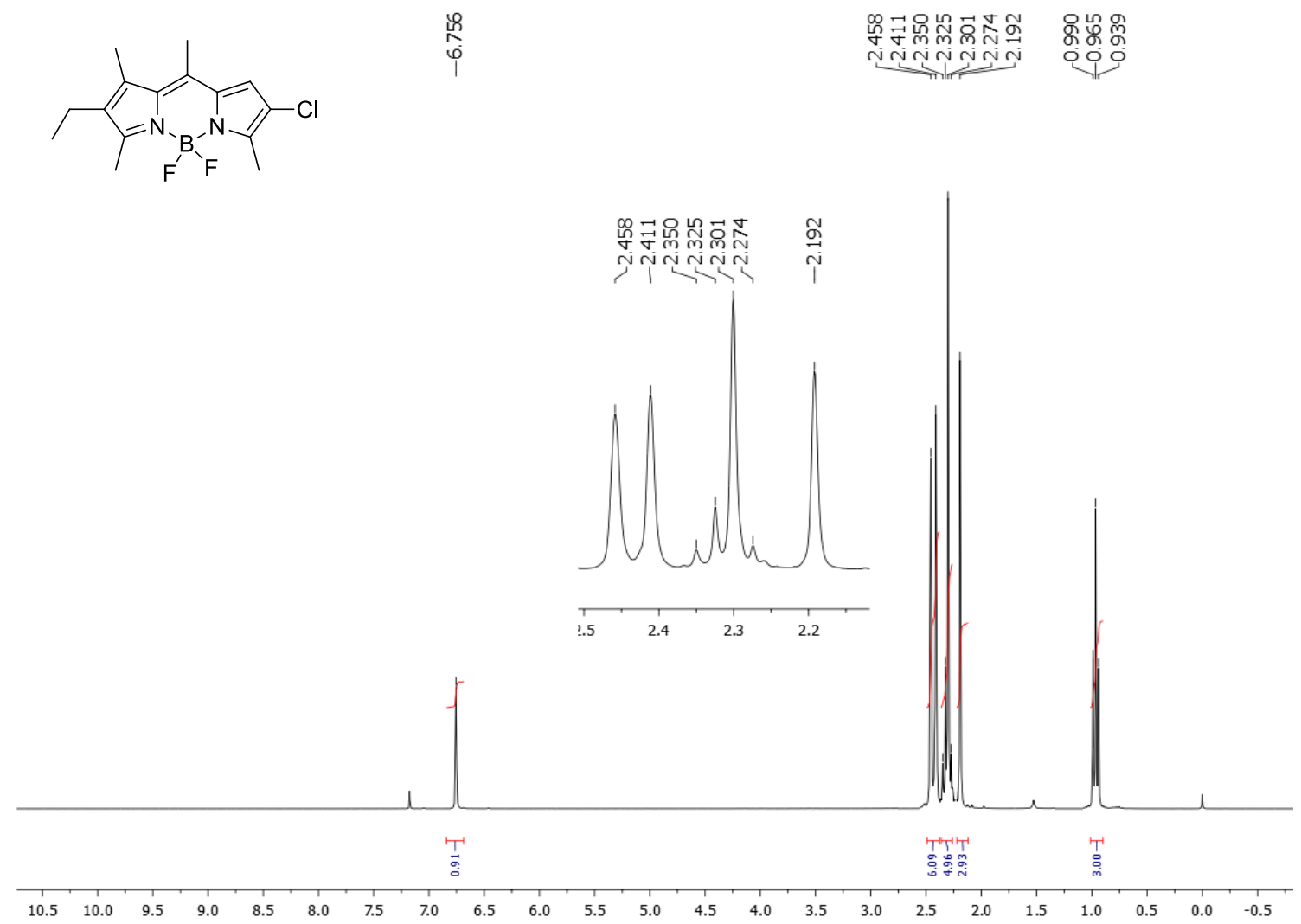

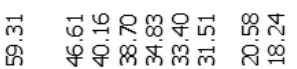

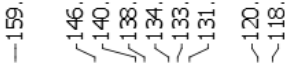

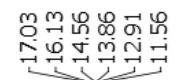

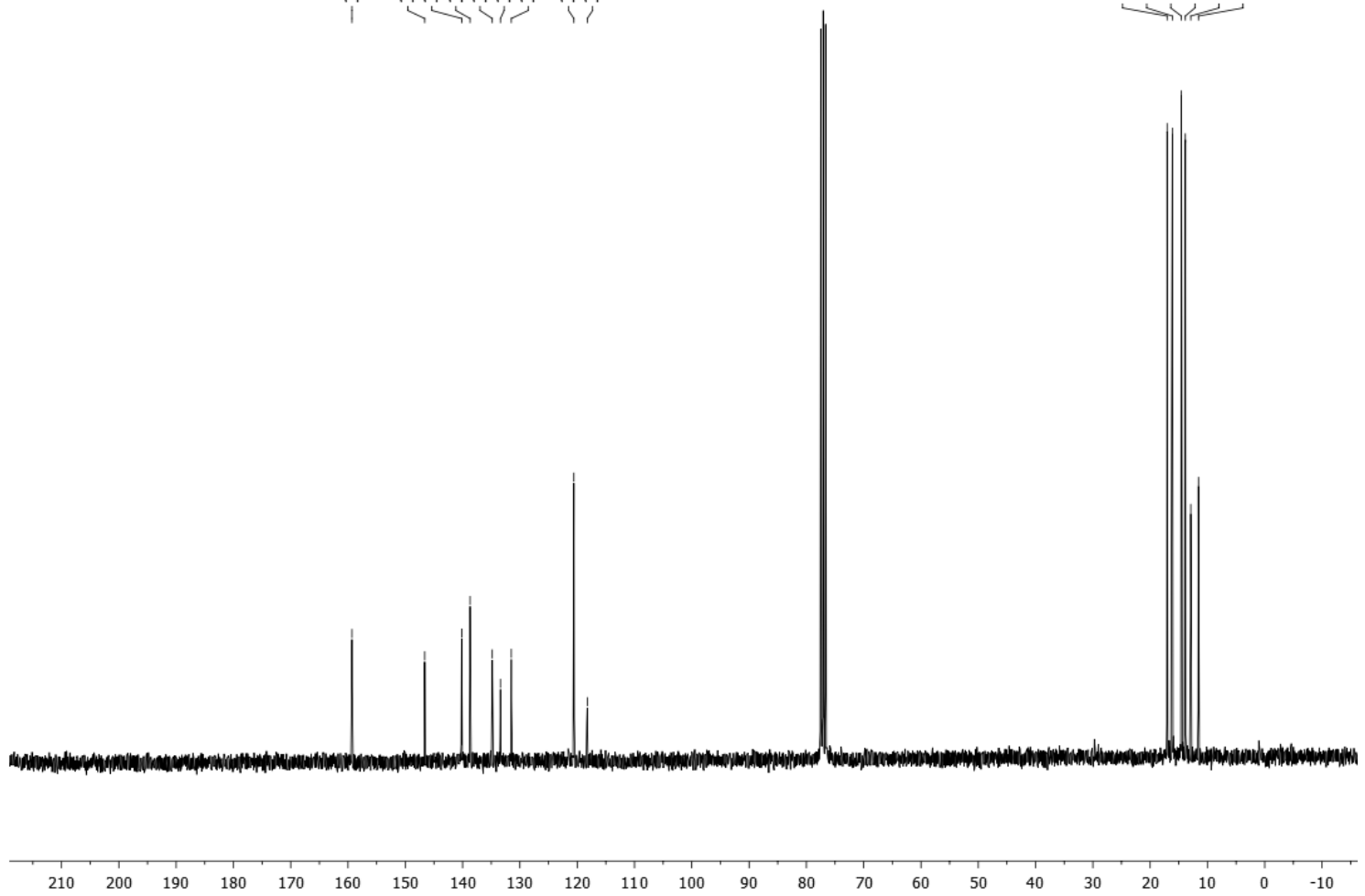


${ }^{1} \mathrm{H}\left(300 \mathrm{MHz}, \mathrm{CDCl}_{3}\right)$ and ${ }^{13} \mathrm{C}\left(75 \mathrm{MHz}, \mathrm{CDCl}_{3}\right)$ NMR spectra of 25

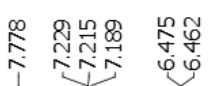

番员员员
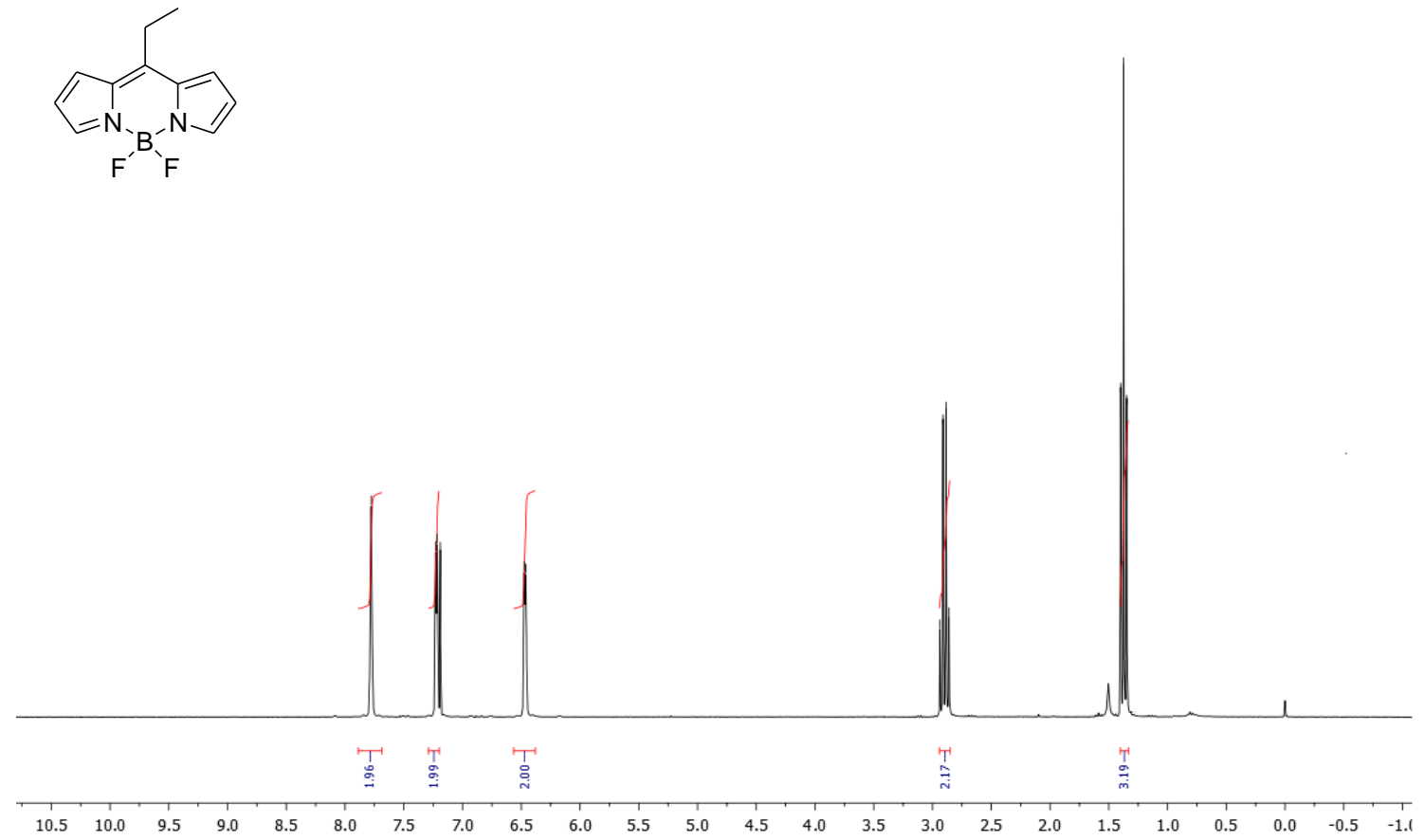

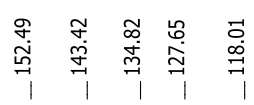

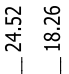

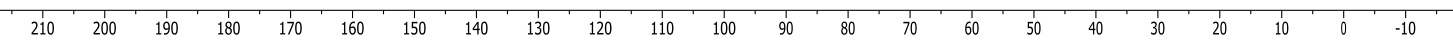


${ }^{1} \mathrm{H}\left(300 \mathrm{MHz}, \mathrm{CDCl}_{3}\right)$ and ${ }^{13} \mathrm{C}\left(75 \mathrm{MHz}, \mathrm{CDCl}_{3}\right)$ NMR spectra of 26

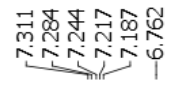

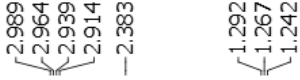<smiles>CCc1c(Br)cc(C(c2ccc(C)cc2)c2cc(Br)c(CC)n2P)n1F</smiles>
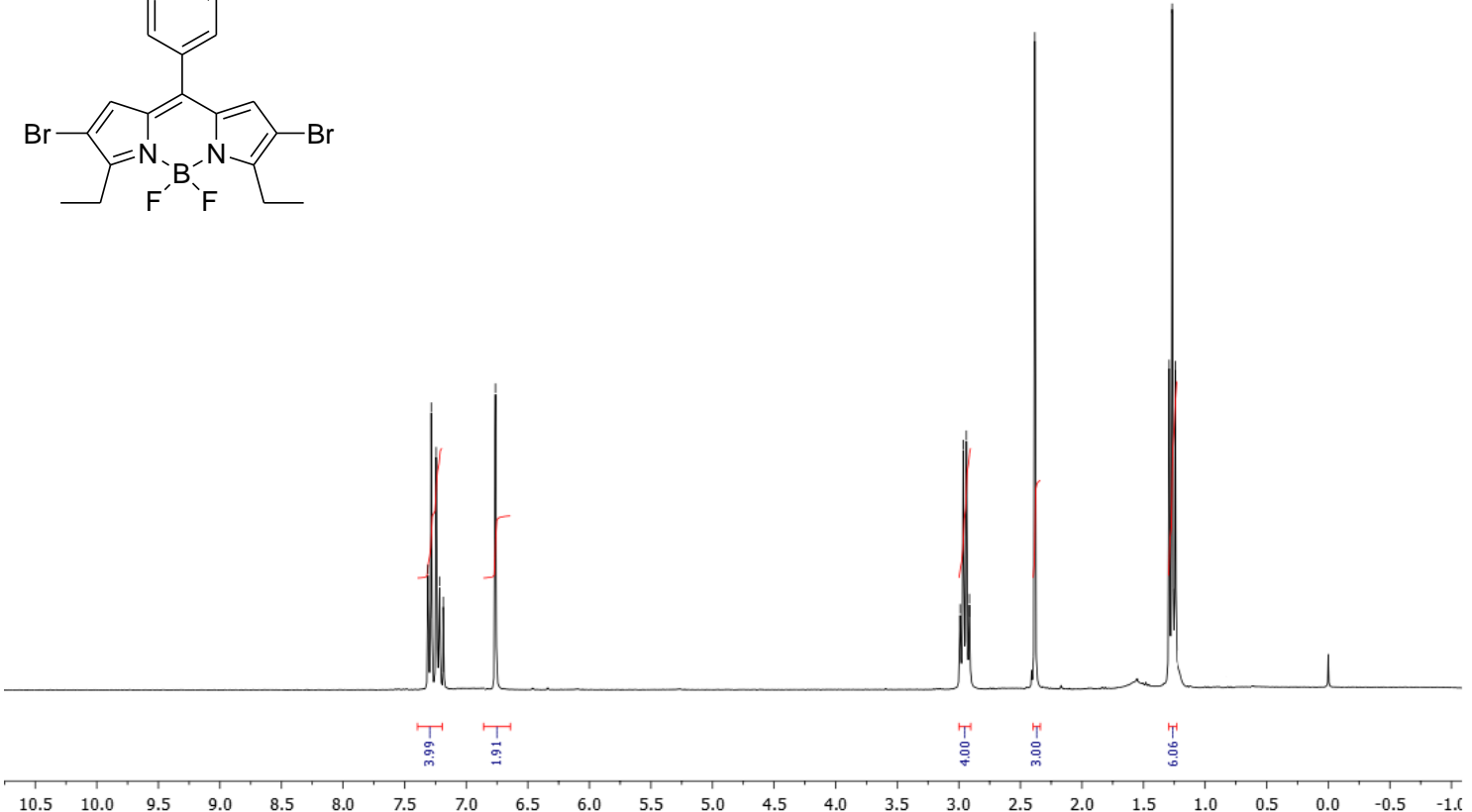

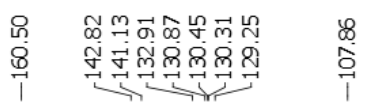

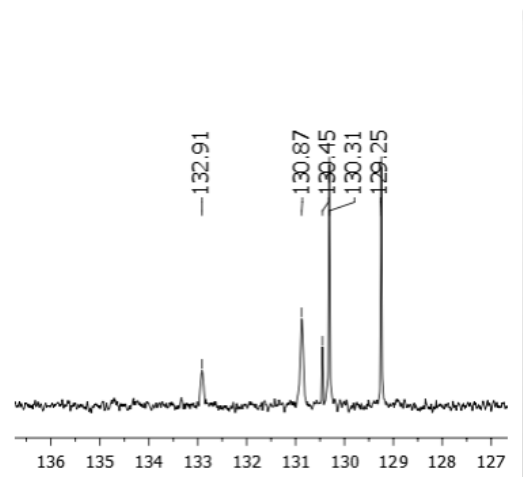

$\begin{array}{llllllllll}136 & 135 & 134 & 133 & 132 & 131 & 130 & 129 & 128 & 127\end{array}$

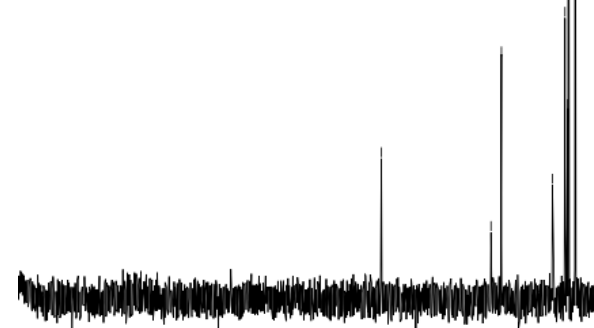

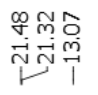

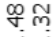

$\overrightarrow{\mathrm{N}}$

$\stackrel{\text { o }}{\text { m }}$

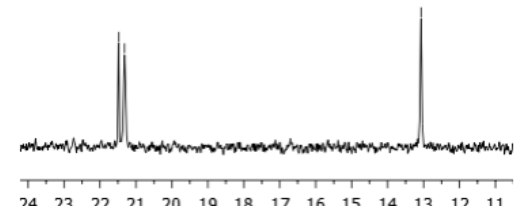

$\begin{array}{lllllllll}24 & 23 & 22 & 21 & 20 & 19 & 18 & 17 & 16\end{array}$

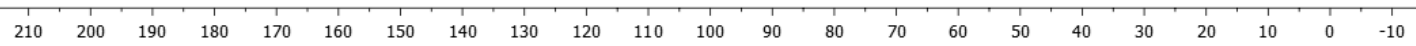


${ }^{1} \mathrm{H}\left(700 \mathrm{MHz}, \mathrm{CDCl}_{3}\right)$ and ${ }^{13} \mathrm{C}\left(176 \mathrm{MHz}, \mathrm{CDCl}_{3}\right)$ NMR spectra of 27

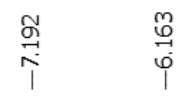

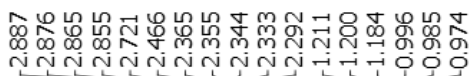

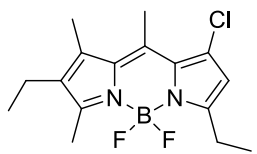
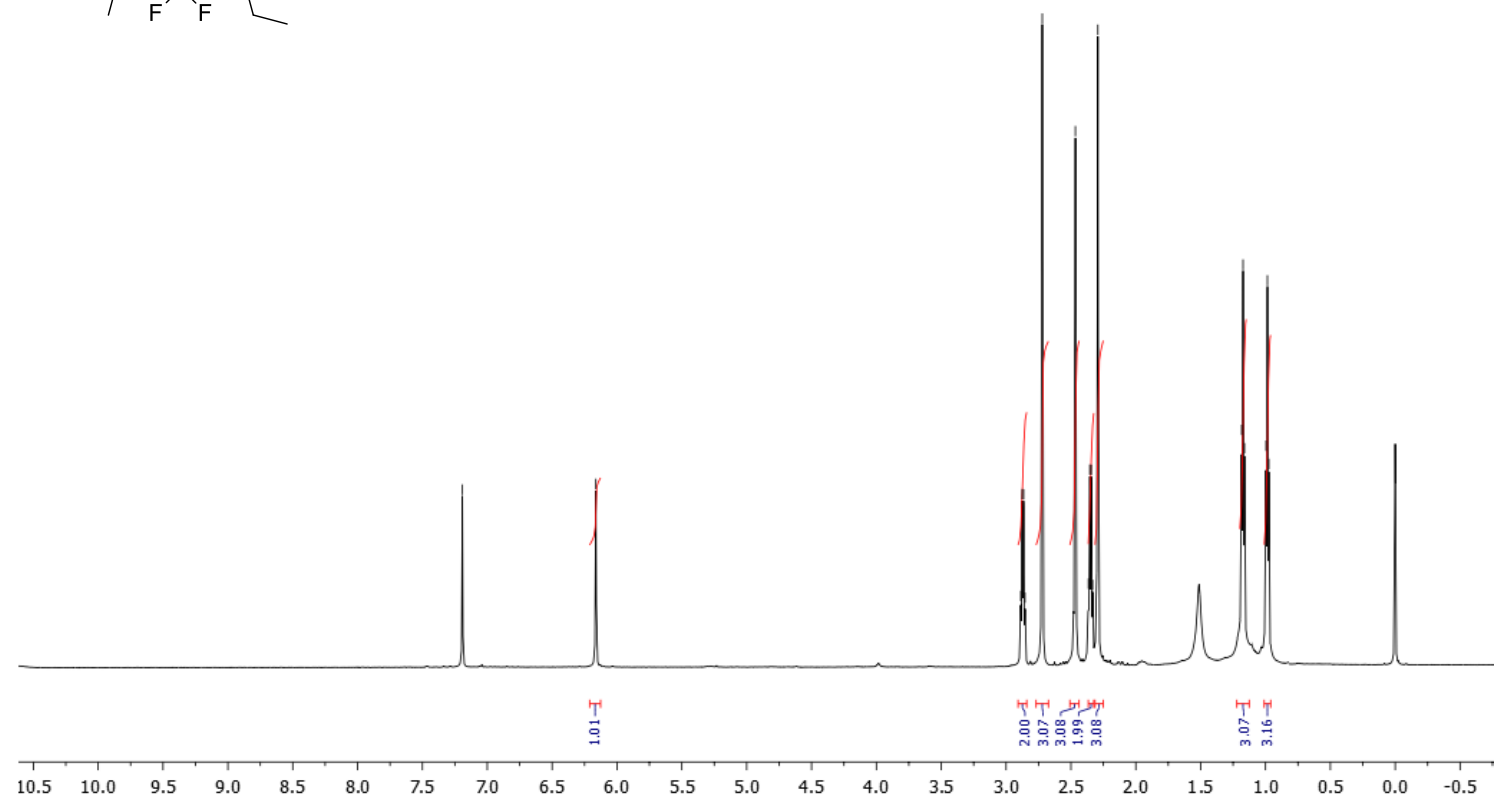

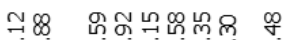

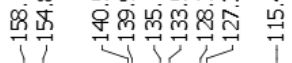

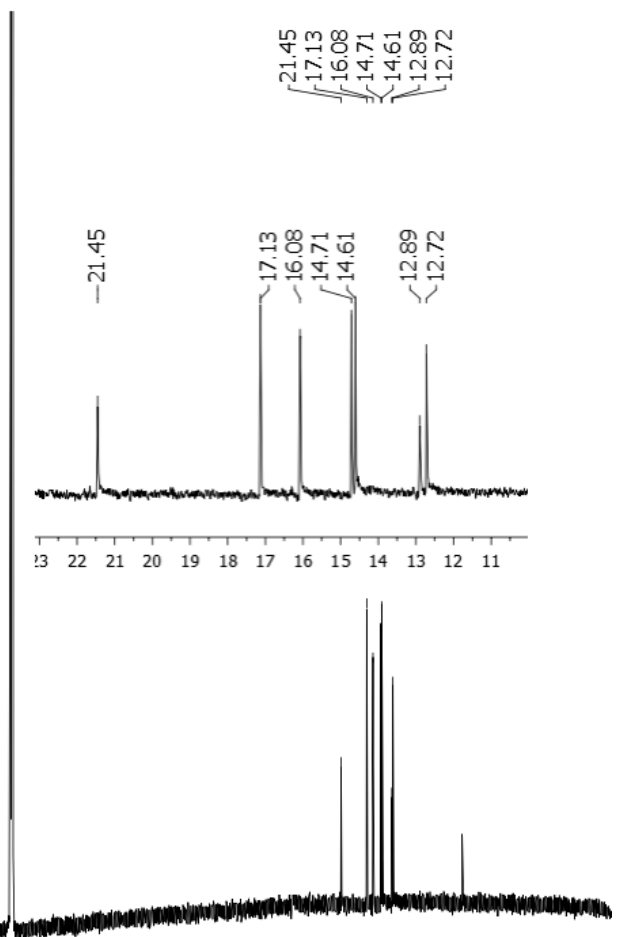

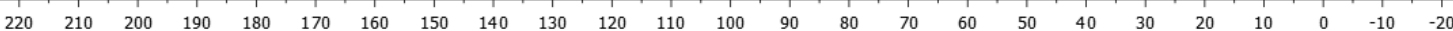


${ }^{1} \mathrm{H}\left(700 \mathrm{MHz}, \mathrm{CDCl}_{3}\right)$ and ${ }^{13} \mathrm{C}\left(176 \mathrm{MHz}, \mathrm{CDCl}_{3}\right) \mathrm{NMR}$ spectra of 28
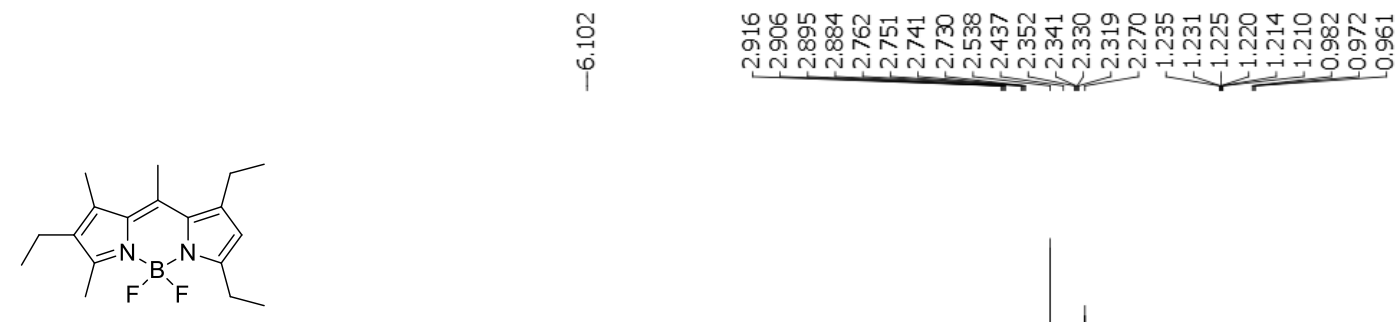

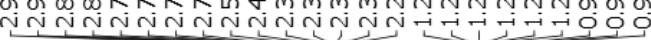

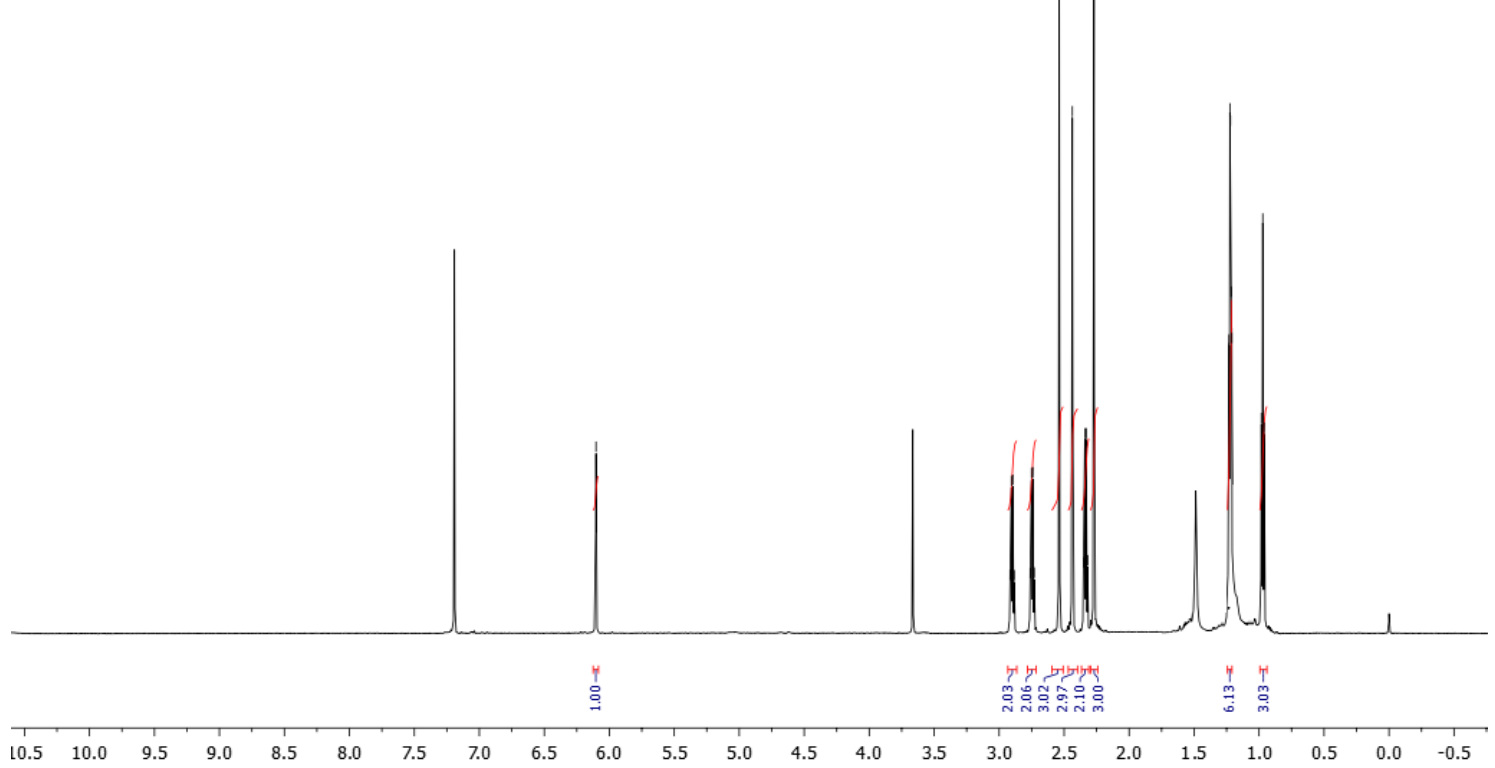

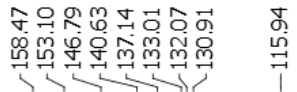

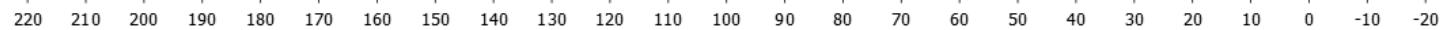

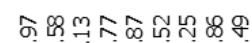

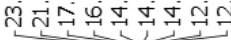

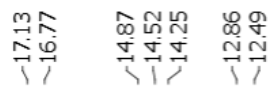

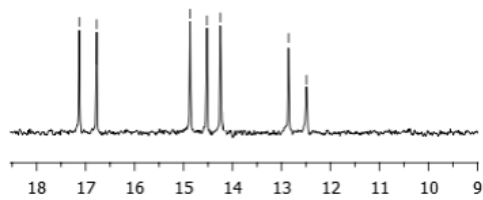

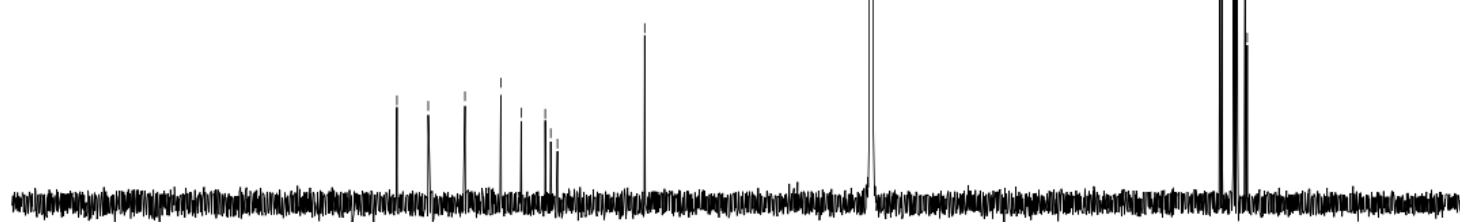


${ }^{1} \mathrm{H}$ NMR (300 MHz, $\mathrm{CDCl}_{3}$ ) spectrum of known $\mathbf{2 9}^{2}$

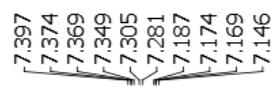

通最实

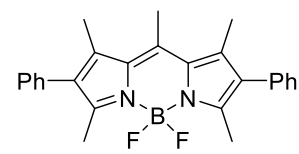

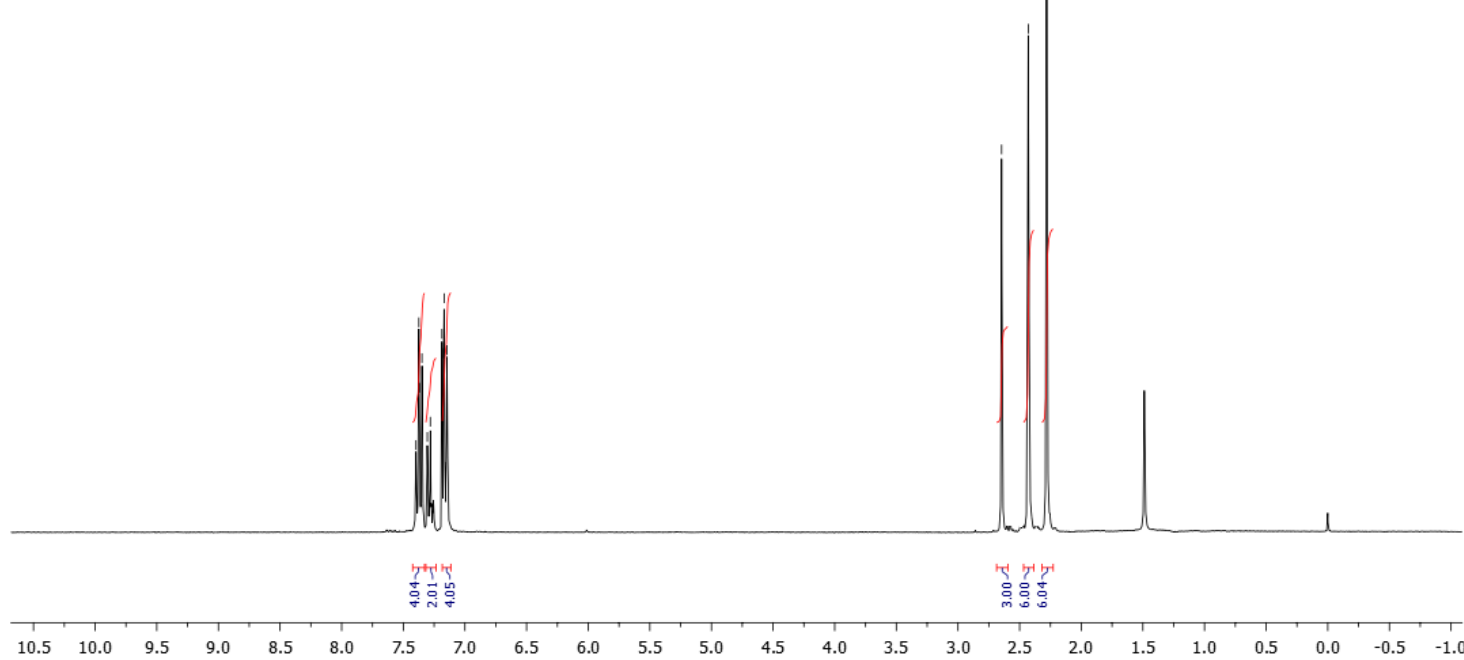


${ }^{1} \mathrm{H}\left(300 \mathrm{MHz}, \mathrm{CDCl}_{3}\right)$ and ${ }^{13} \mathrm{C}\left(75 \mathrm{MHz}, \mathrm{CDCl}_{3}\right)$ NMR spectra of 30a
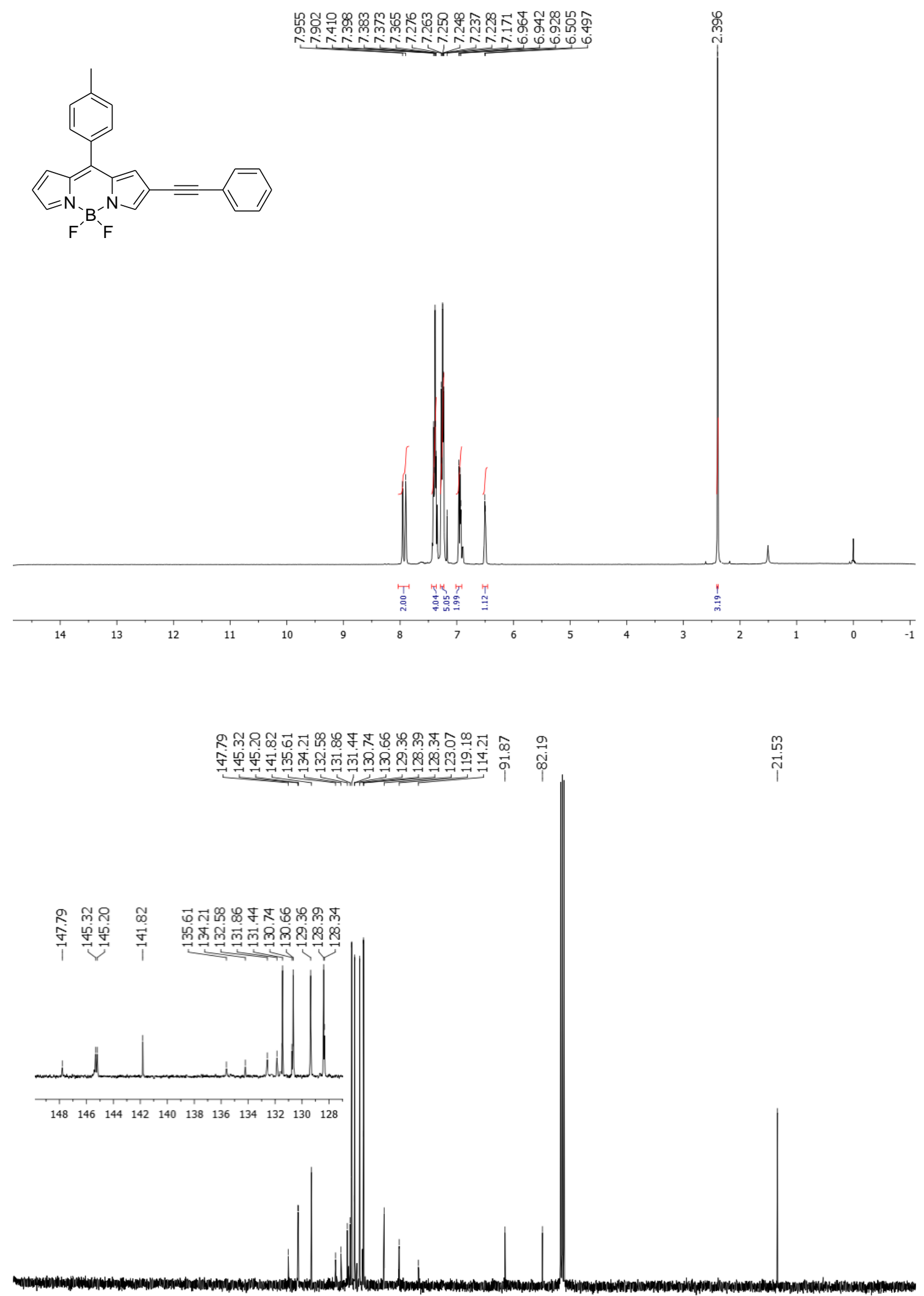

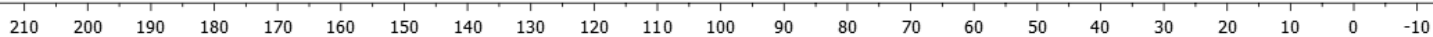


${ }^{1} \mathrm{H}\left(300 \mathrm{MHz}, \mathrm{CDCl}_{3}\right)$ and ${ }^{13} \mathrm{C}\left(75 \mathrm{MHz}, \mathrm{CDCl}_{3}\right)$ NMR spectra of $\mathbf{3 0 b}$
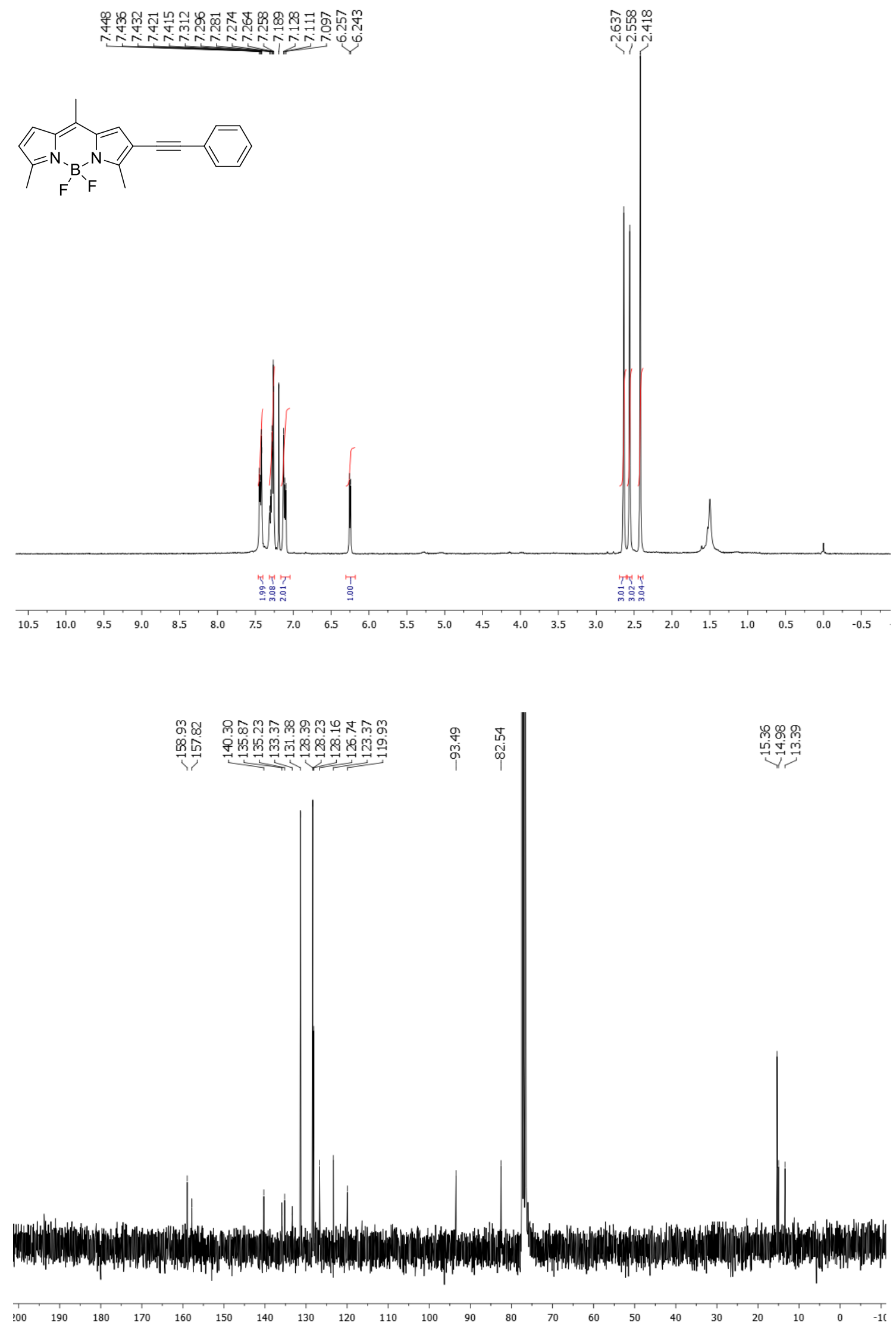
${ }^{1} \mathrm{H}\left(700 \mathrm{MHz}, \mathrm{CDCl}_{3}\right)$ and ${ }^{13} \mathrm{C}\left(176 \mathrm{MHz}, \mathrm{CDCl}_{3}\right)$ NMR spectra of 31
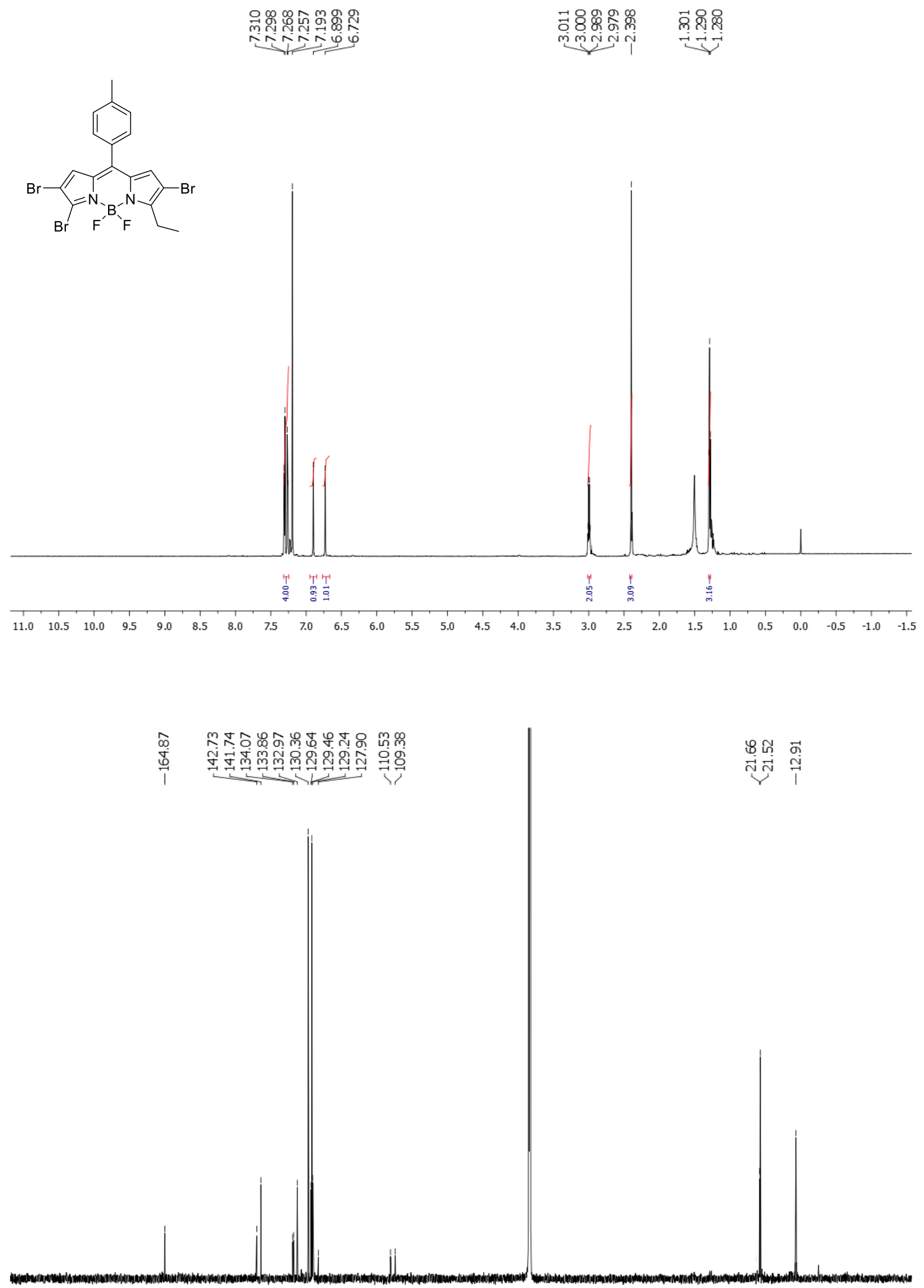

200 1 


\section{1D NOESY Spectra (in green)}

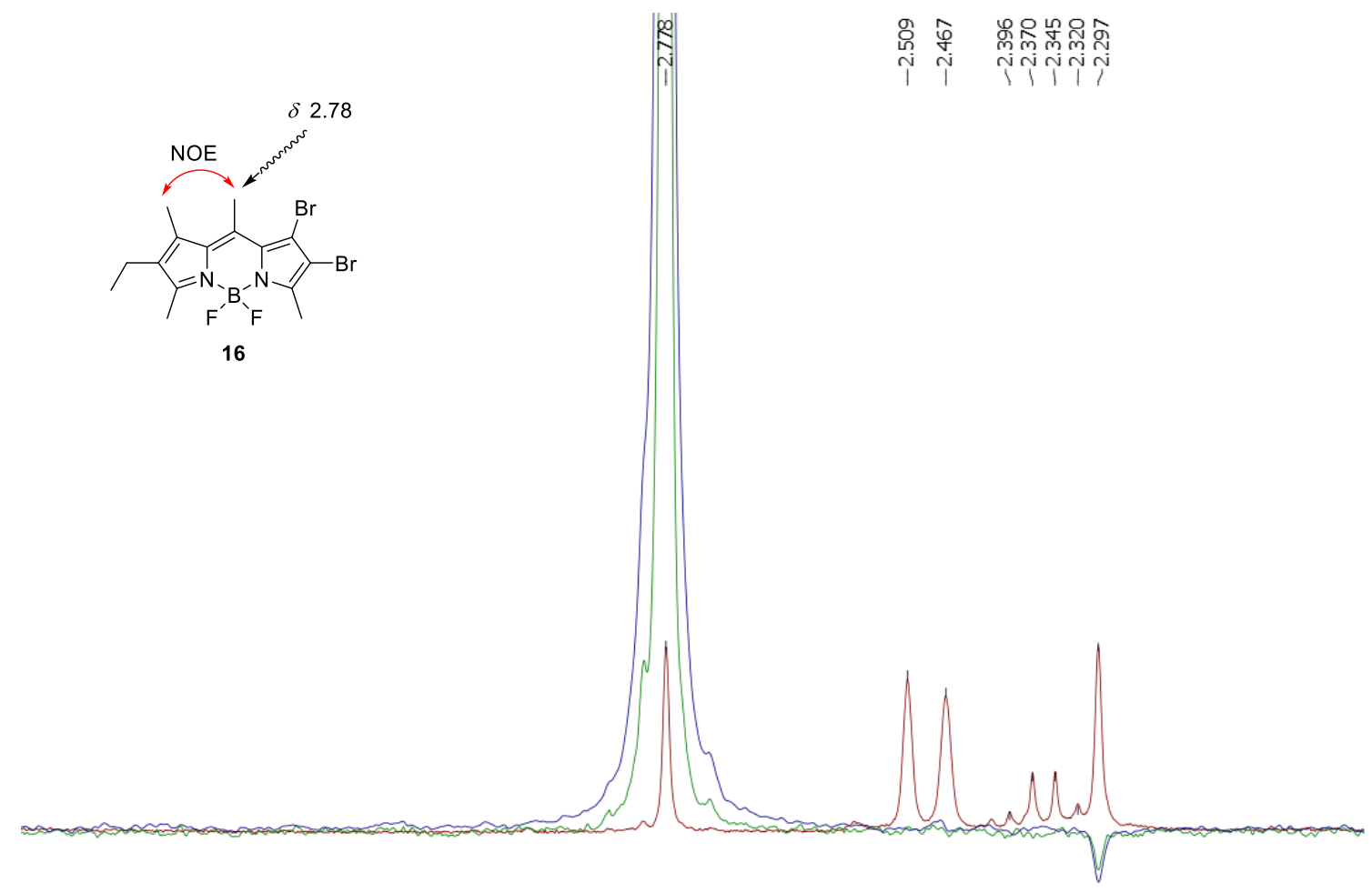

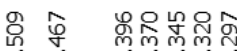

i Ninin

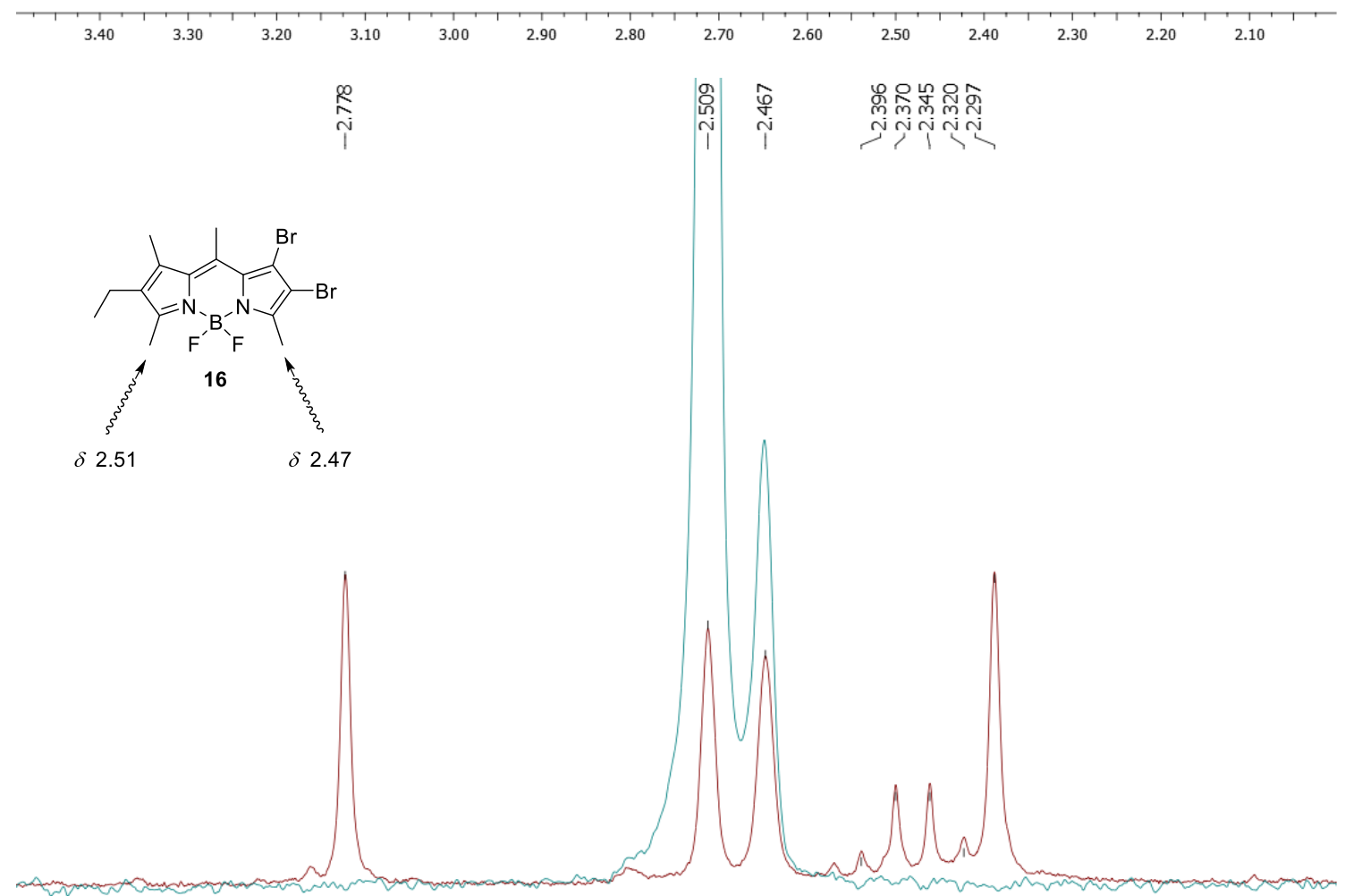

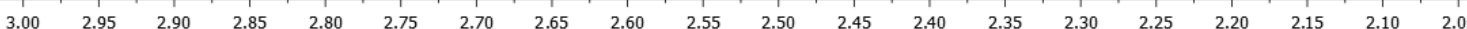



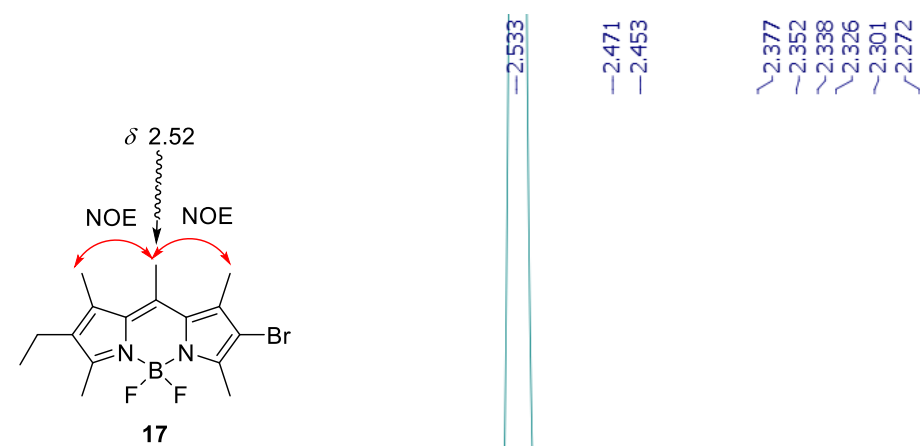

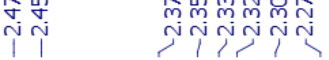
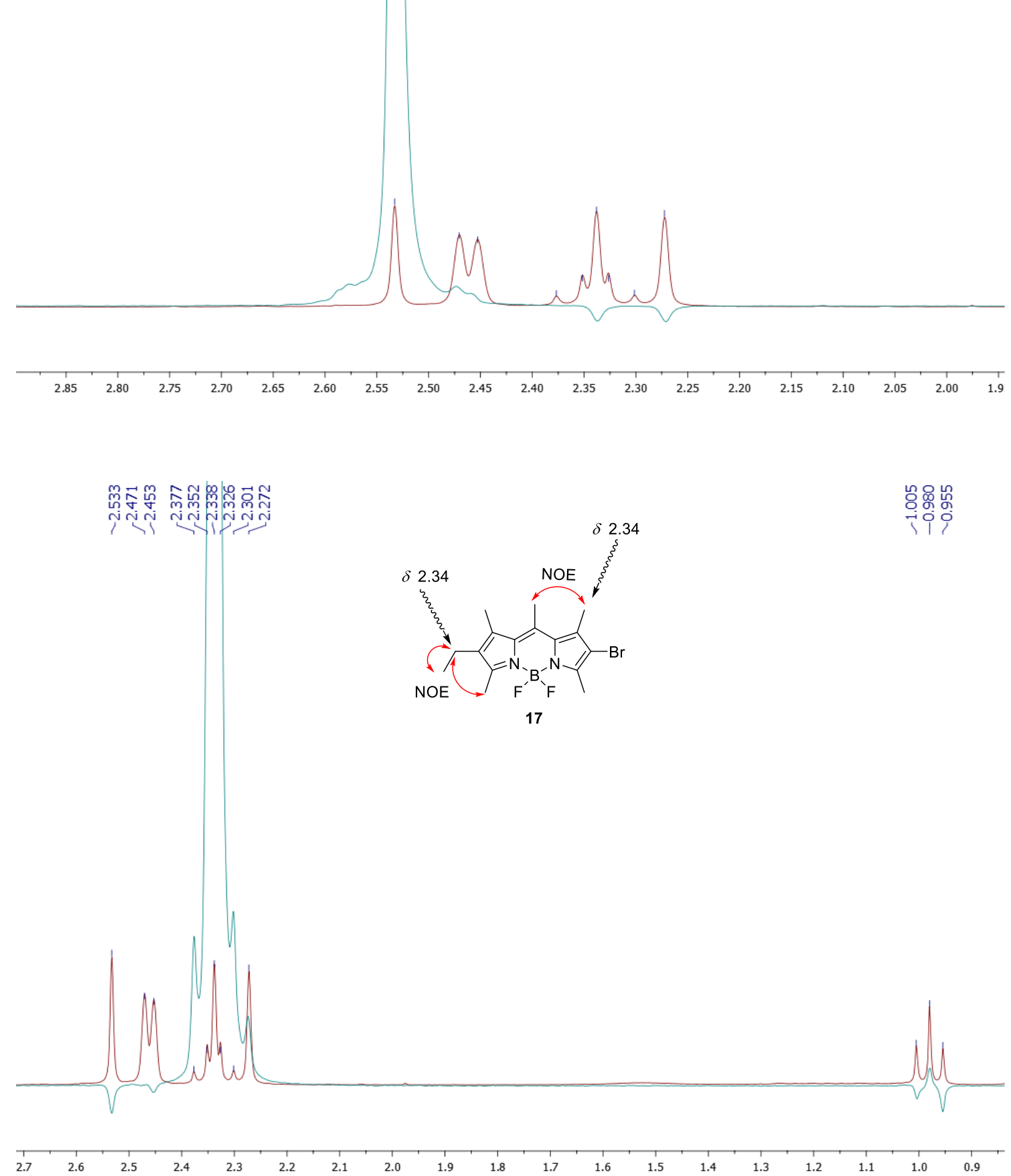


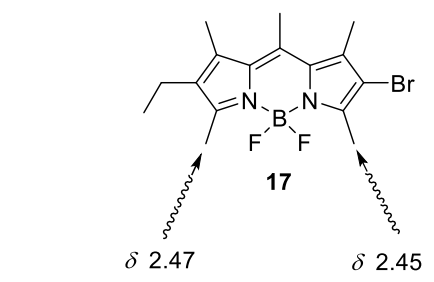

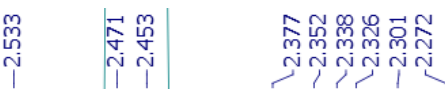
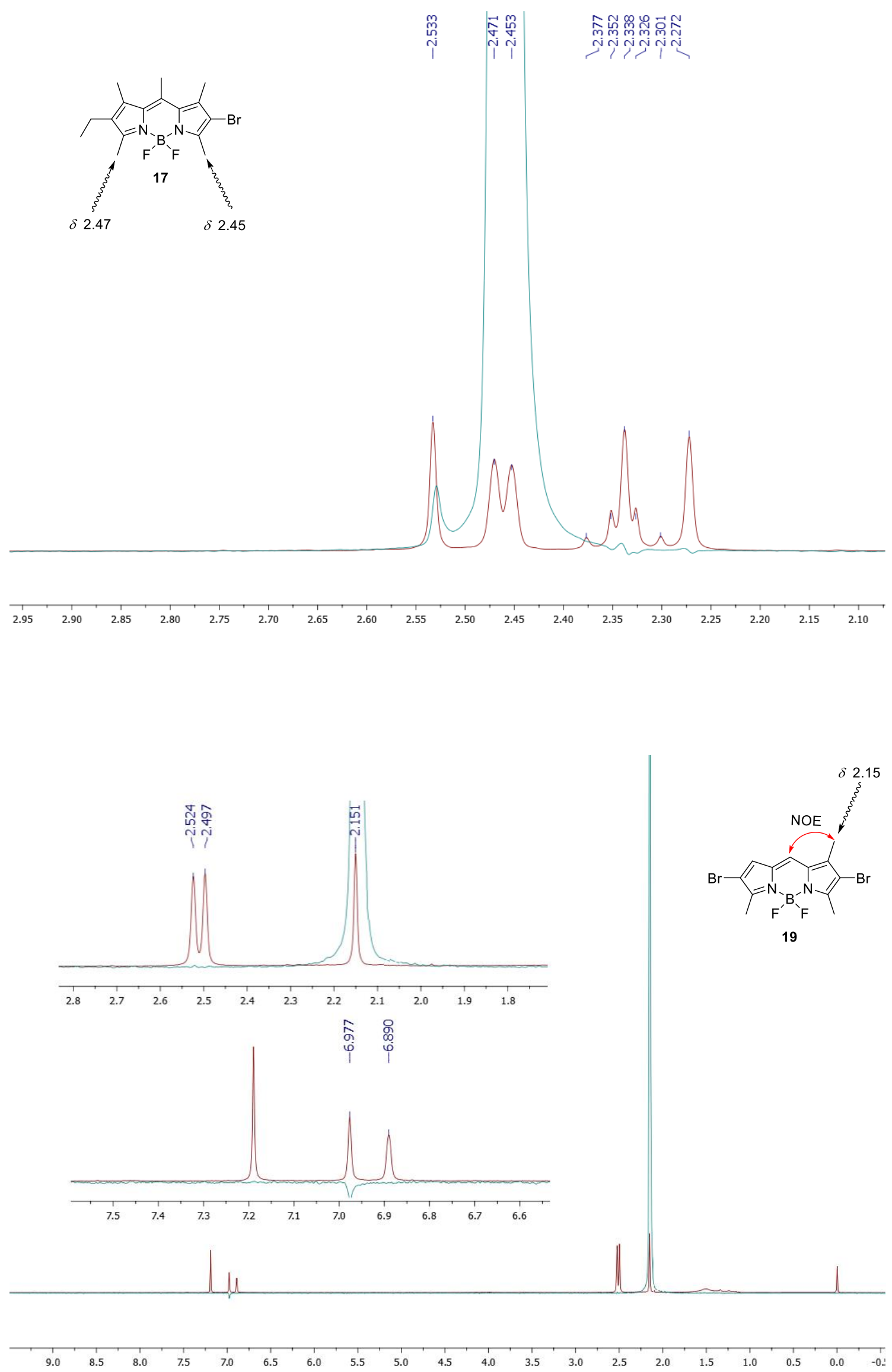

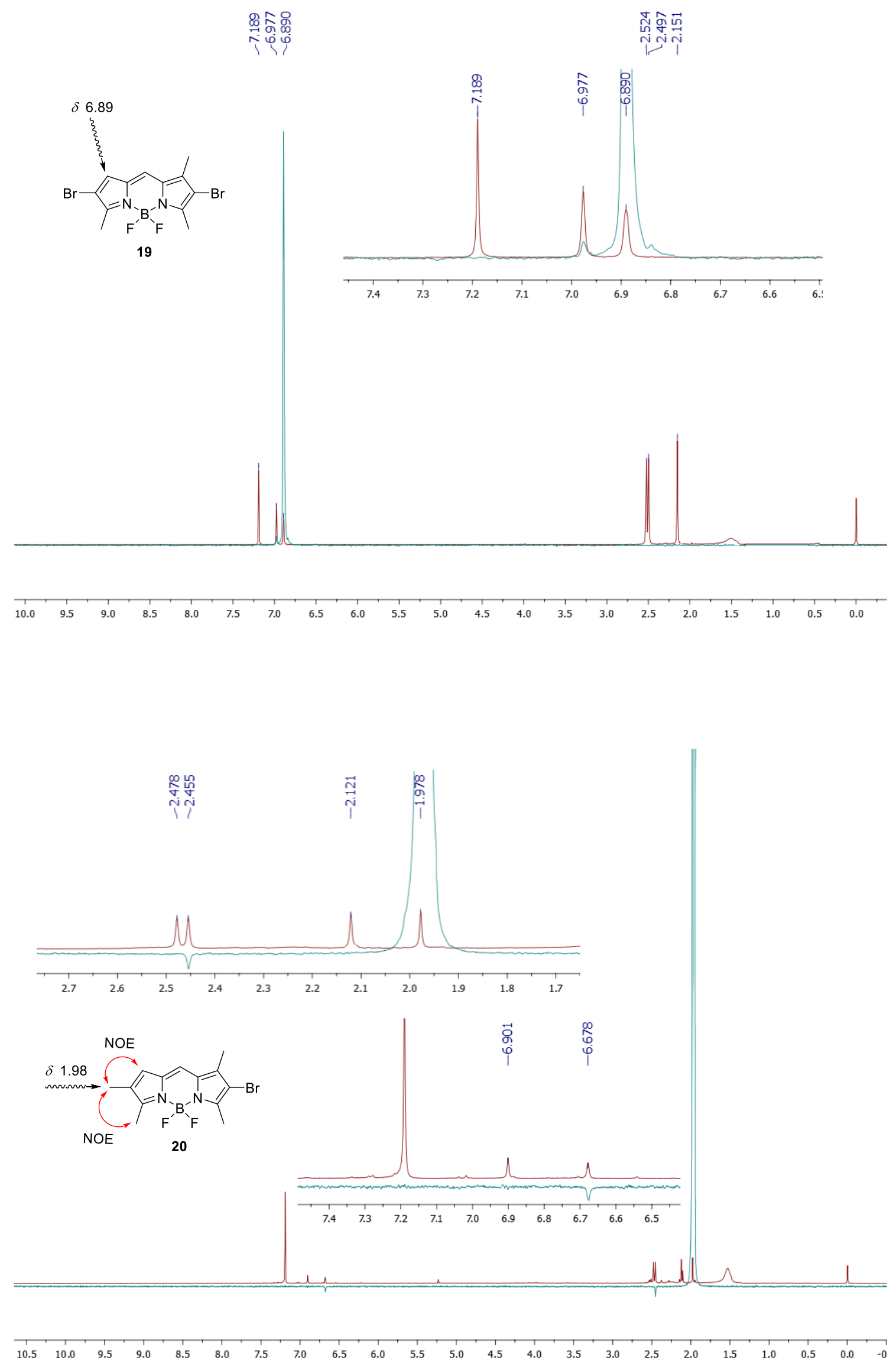

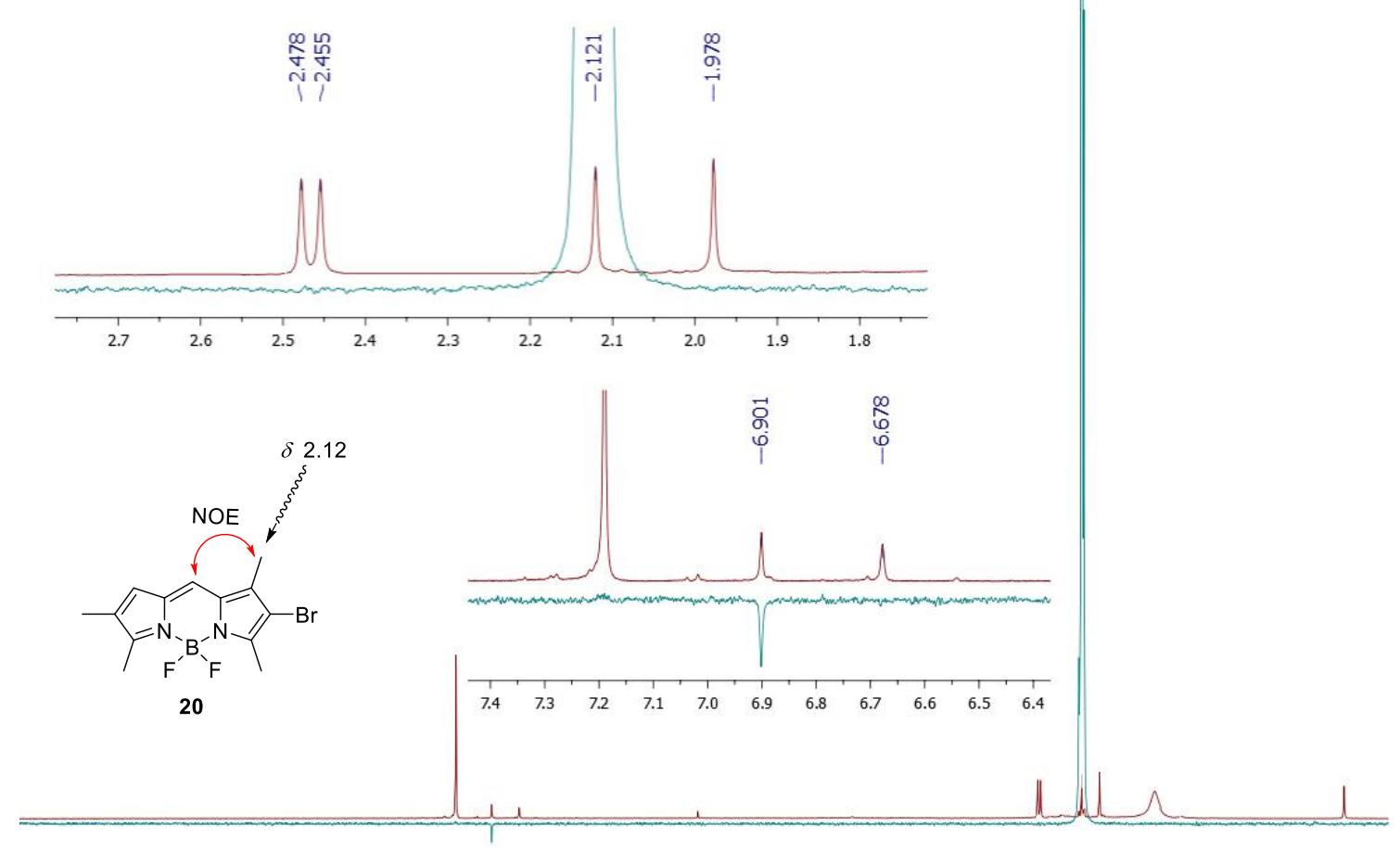

\begin{tabular}{lllllllllllllllllllllll}
\hline & 10.5 & 10.0 & 9.5 & 9.0 & 8.5 & 8.0 & 7.5 & 7.0 & 6.5 & 6.0 & 5.5 & 5.0 & 4.5 & 4.0 & 3.5 & 3.0 & 2.5 & 2.0 & 1.5 & 1.0 & 0.5 & 0.0
\end{tabular} 


\section{2D HMBC Spectra}

HMBC spectrum of $\mathbf{1 6}$
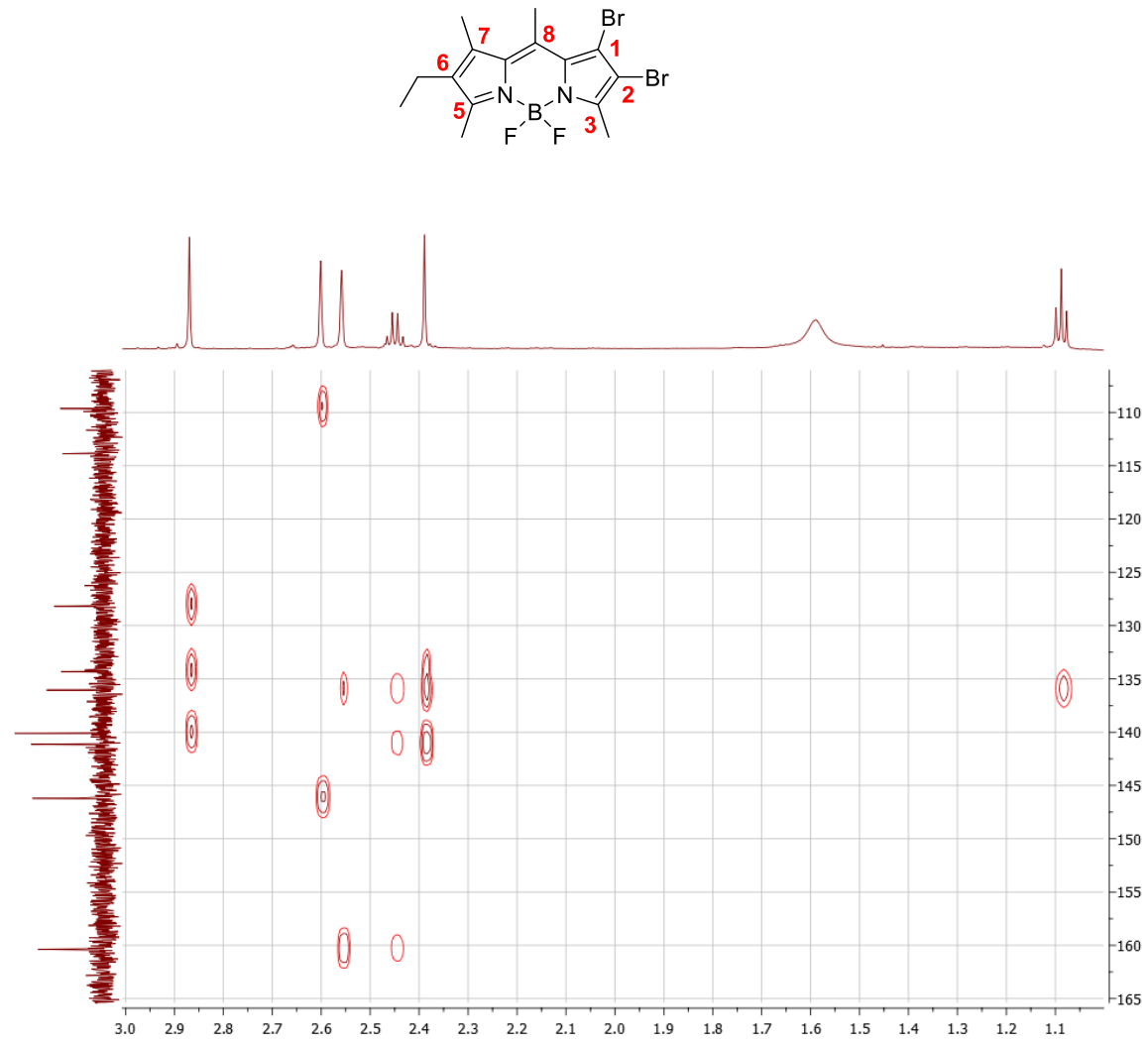
HMBC spectrum of $\mathbf{1 7}$

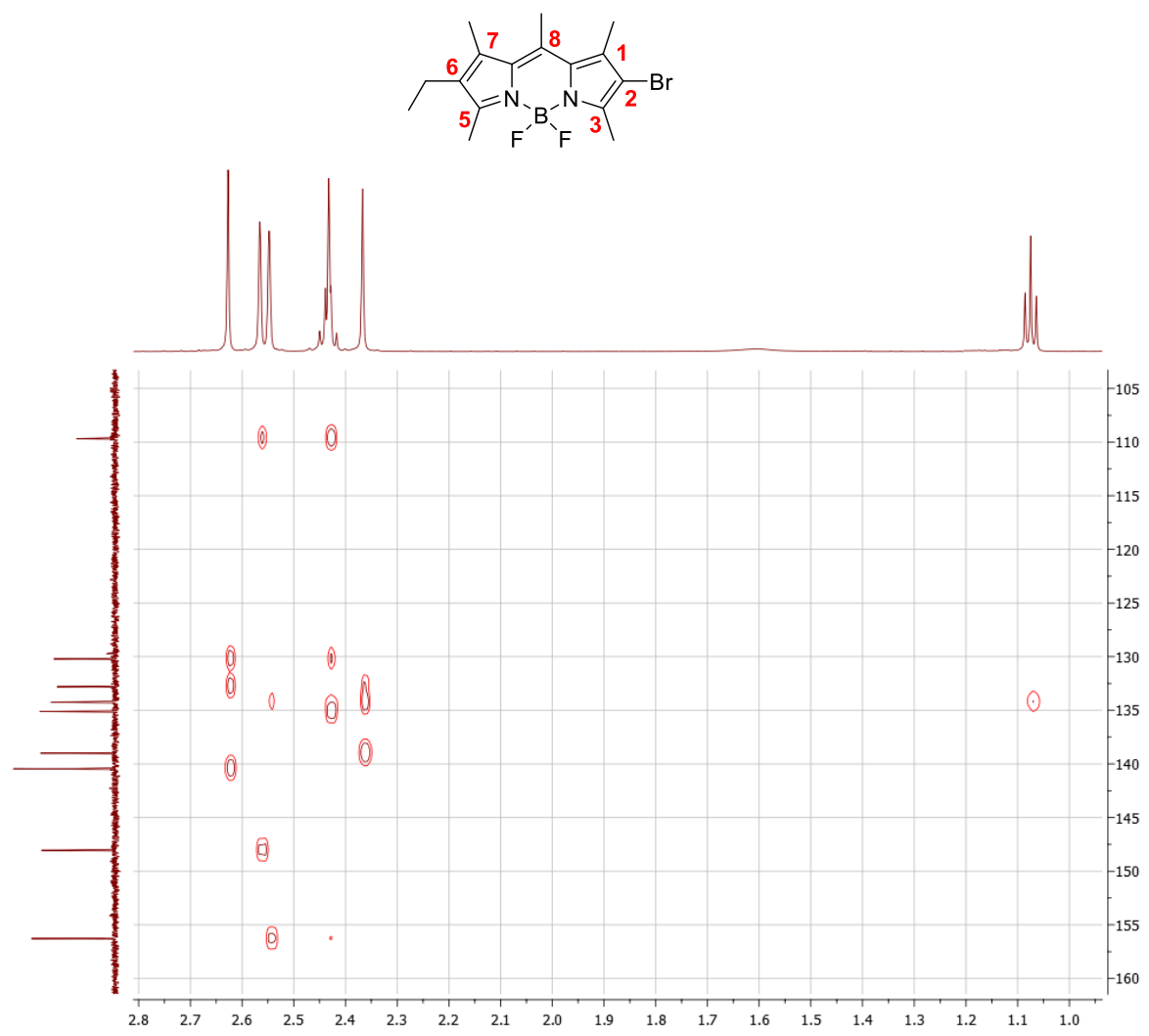


HMBC spectra of $\mathbf{1 9}$

$$
\text { (1) }
$$
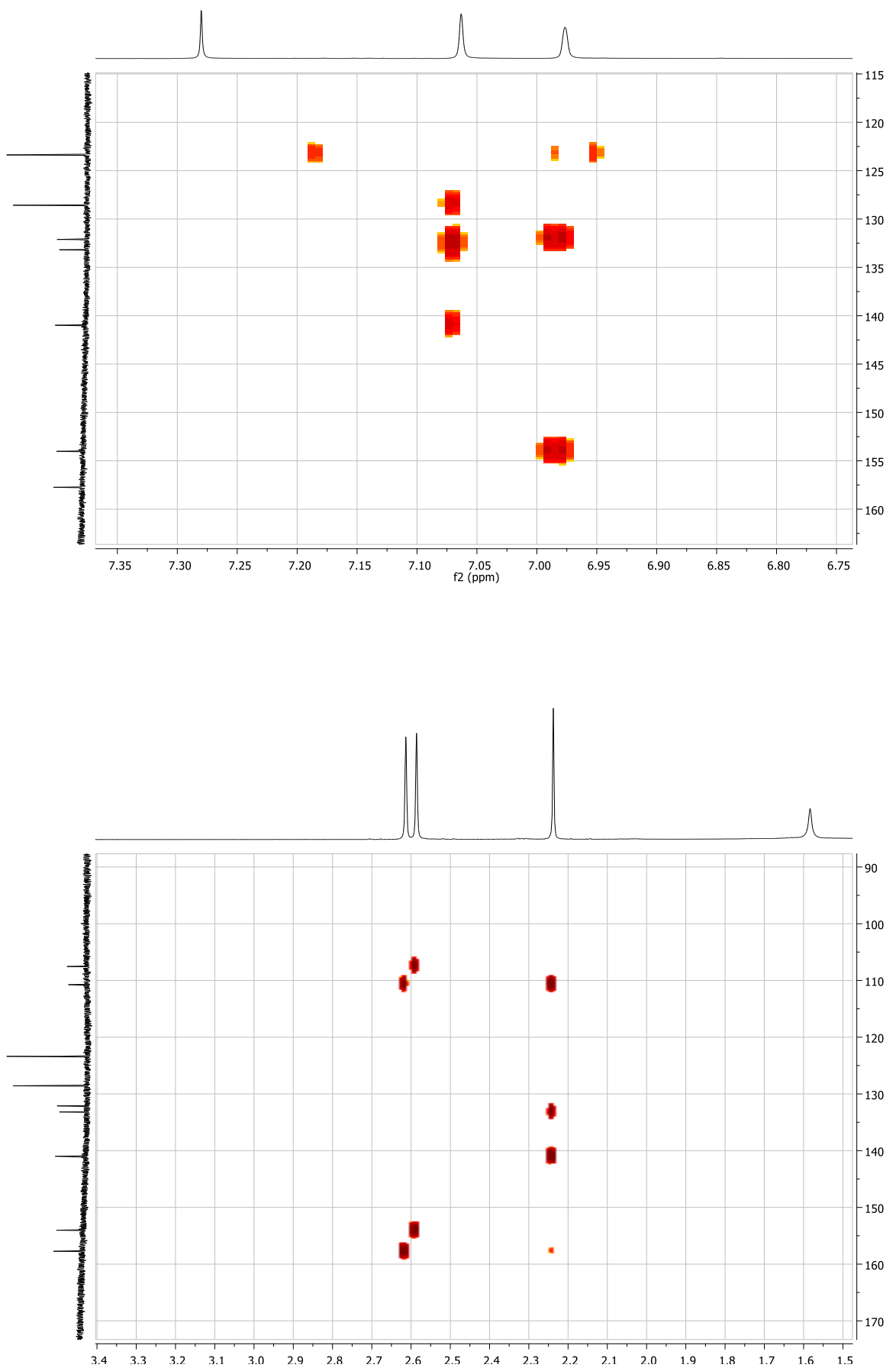
HMBC spectra of $\mathbf{2 0}$

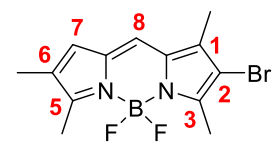
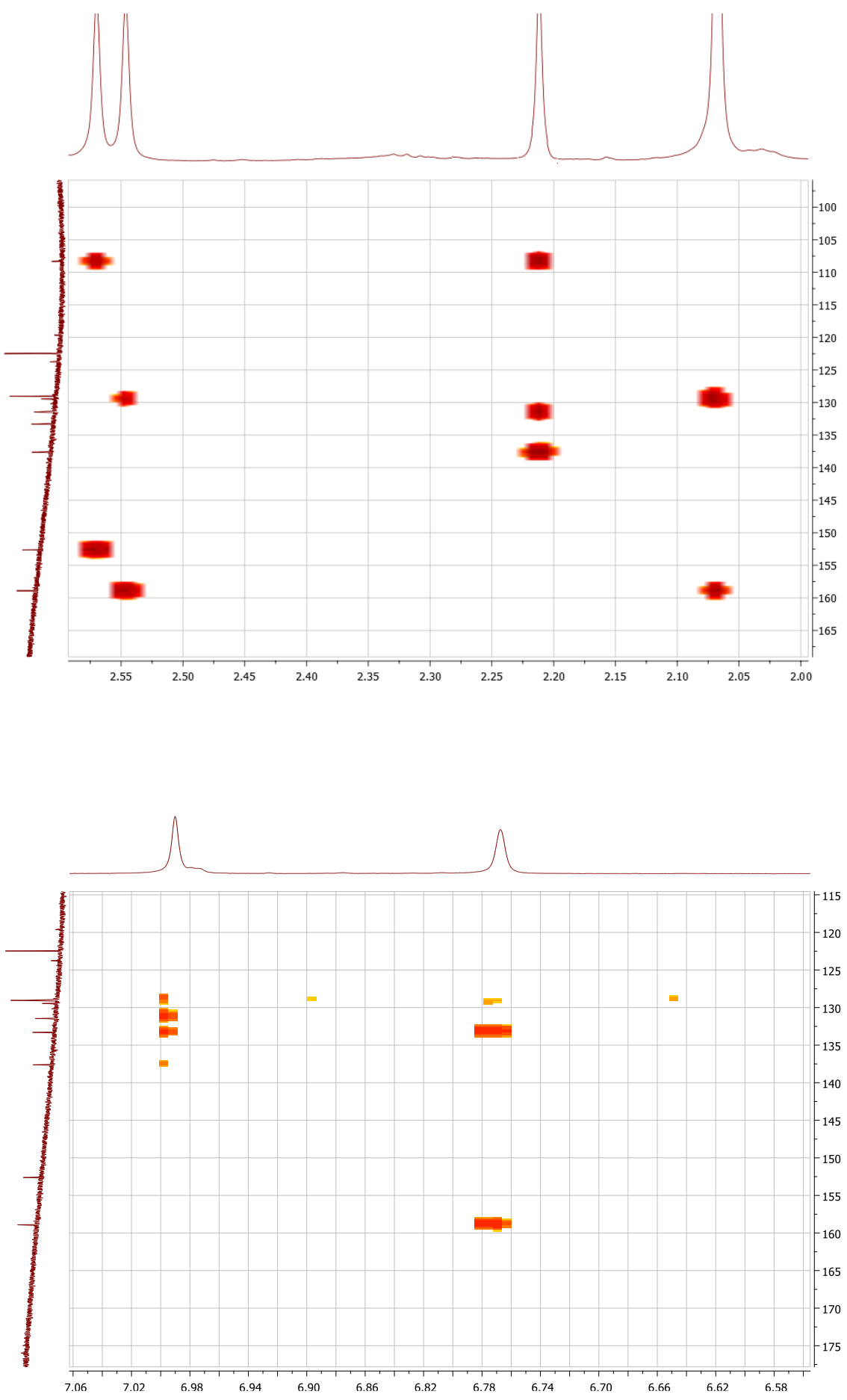


\section{References}

1. Leen, V.; Miscoria, D.; Yin, S.; Filarowski, A.; Ngongo, J. M.; Van der Auweraer, M.; Boens, N.; Dehaen, W. J. Org. Chem. 2011, 76, 8168-8176.

2. Boyer, J. H.; Haag, A. M.; Sathyamoorthi, G.; Soong, M. L.; Thangaraj, K.; Pavlopoulos, T. G. Heteroatom Chem. 1993, 4, 39-49. 